Rosana Ravagnani Campedelli

\title{
TRATAMENTO CONSERVADOR SIMPLIFICADO EM PACIENTES PORTADORES DE OSTEOARTROSE DE JOELHO
}

\author{
Dissertação apresentada à Faculdade \\ Israelita de Ciências da Saúde Albert \\ Einstein para obtenção do Título de Mestre \\ em Ciências da Saúde.
}

São Paulo 


\title{
Rosana Ravagnani Campedelli
}

\section{TRATAMENTO CONSERVADOR SIMPLIFICADO EM PACIENTES PORTADORES DE OSTEOATROSE DE JOELHO}

\author{
Dissertação apresentada à Faculdade \\ Israelita de Ciências da Saúde Albert \\ Einstein para obtenção do Título de Mestre \\ em Ciências da Saúde.
}

Orientador: Prof. Dr. Mario Ferretti Filho Coorientadora: Profa. Dra. Eliane Antonioli 
C193t

Campedelli, Rosana Ravagnani

Tratamento conservador simplificado em pacientes portadores de osteoartrose de joelho / Rosana Ravagnani Campedelli. -- São Paulo, 2020.

xii, $52 \mathrm{f}$.

Dissertação (Mestrado) - Faculdade Israelita de Ciências da Saúde Albert Einstein. Instituto Israelita de Ensino e Pesquisa Albert Einstein. Programa de Pós-Graduação em Ciências da Saúde.

Título em inglês: Simplified conservative treatment for patients with knee osteoarthritis.

1. Osteoartrite. 2. Terapia por exercício. 3. Medição da dor. 4. Qualidade de vida. 5. Força muscular.

NLM - WE 870

Elaborada pelo Sistema Einstein Integrado de Bibliotecas 
FACULDADE ISRAELITA DE CIÊNCIAS DA SAÚDE ALBERT EINSTEIN

Coordenador do Curso de Pós-Graduação: Prof. Dr. Luiz Vicente Rizzo 
Rosana Ravagnani Campedelli

\title{
TRATAMENTO CONSERVADOR SIMPLIFICADO EM PACIENTES PORTADORES DE OSTEOATROSE DE JOELHO
}

Presidente da banca: Prof. Dr. Mario Ferretti Filho

\author{
BANCA EXAMINADORA
}

Membros titulares:

Profa. Dra. Luciana Diniz Janot de Matos

Prof. Dr. Rodrigo Pereira Guimarães

Prof. Dr. Alberto de Castro Pochini

Membros suplentes:

Prof. Dr. Reynaldo Jesus Garcia Filho

Prof. Dr. Paulo Roberto Veiga Quemelo

Aprovada em: 06/08/2020. 


\section{Dedicatória}

Ao Prof. Dr. Ricardo Aun. 


\section{Agradecimentos}

Ao meu querido Ronan, pela paciência e incentivo durante todos os anos do desenvolvimento desta pesquisa.

Aos meus pais, Pedro e Irma, pelo esforço de suas vidas, que me permitiu chegar até aqui.

A minha coorientadora Dra. Eliane Antonioli, pelo apoio e amizade durante todos estes anos.

Ao meu orientador, Prof. Dr. Mario Ferretti Filho, pela oportunidade.

Aos doutores Rafael Fonseca, Frank Beretta, Alessandro Zorzi e Rogerio Teixeira pelo enorme apoio durante todo o projeto.

Ao Felipe B. D. Oliveira pela participação no desenvolvimento da pesquisa.

A querida Rebeca Barqueiro de Oliveira pela ajuda na leitura e organização dos e-mails.

A Isadora Orlando de Oliveira e Mariana Rosada, pelas sugestões dadas para o desenvolvimento desta pesquisa.

A Marcos Eduardo Boquembuzo, Elson Lima Junior, Ana Paula Leite e Natalia Candeloro pelo apoio no desenvolvimento da pesquisa prática.

Ao serviço de estatística do Instituto Israelita de Ensino e Pesquisa do Hospital Israelita Albert Einstein.

A todos os participantes desta pesquisa, que doaram seu tempo e seus corpos para que esta acontecesse.

À Fundação de Amparo à Pesquisa do Estado de São Paulo (FAPESP) pelo financiamento desta pesquisa através do edital em parceria com The Ohio State University (FAPESP/OSU: 2015/50274-5). 
"Nada lhe posso dar a não ser a oportunidade, o impulso, a chave. Eu o ajudarei a tornar visível o seu próprio mundo, e isso é tudo".

(Hermann Hesse) 


\section{Sumário}

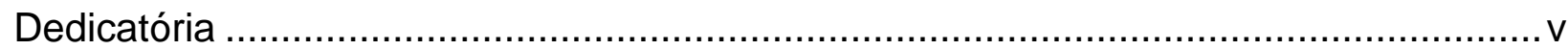

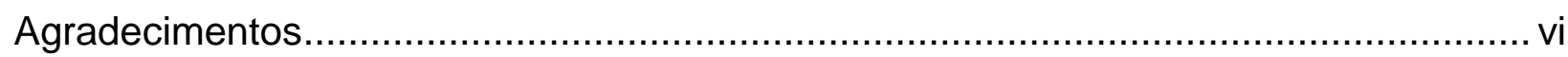

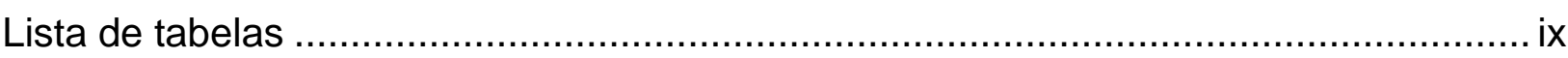

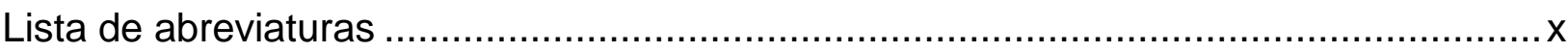

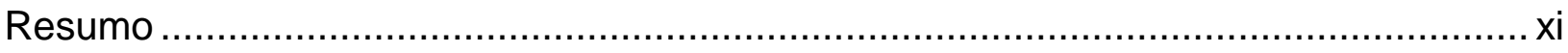

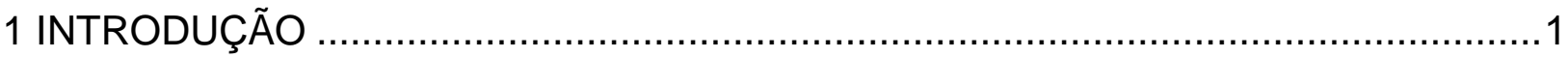

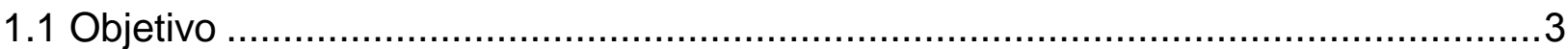

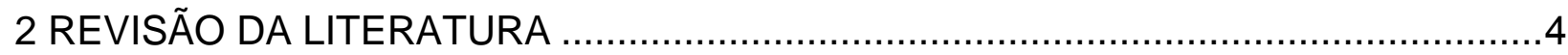

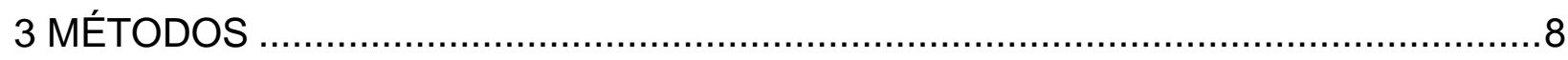

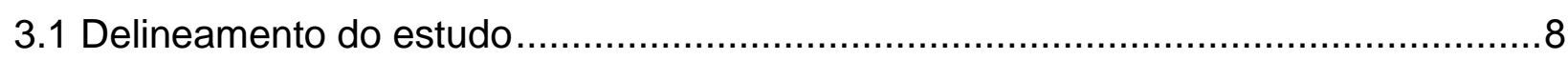

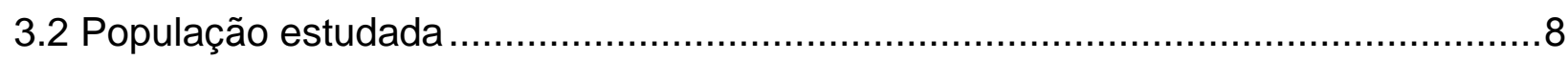

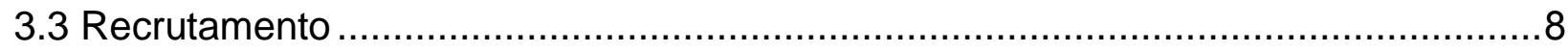

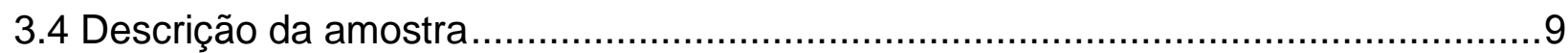

3.4.1 Critérios de inclusão .................................................................................. 10

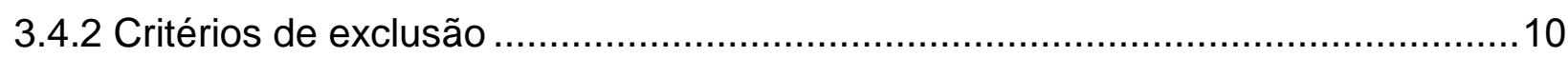

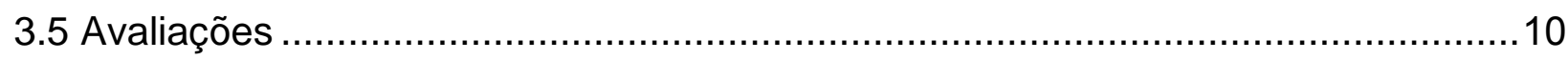

3.6 Medidas de desfecho.......................................................................... 11

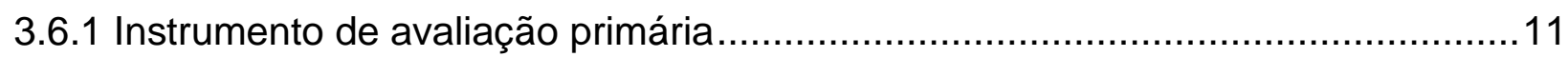

3.6.1.1 Western Ontario e McMaster Universities .............................................11

3.6.2 Instrumentos de avaliação secundária ...................................................... 11

3.6.2.1 Questionário relacionado com a saúde e qualidade de vida ..........................11

3.7 Protocolo de reabilitação .................................................................... 15

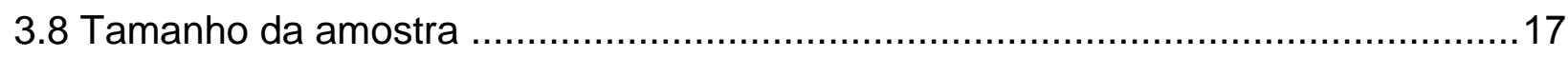

3.9 Análise estatística......................................................................... 17

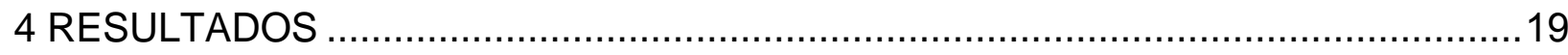

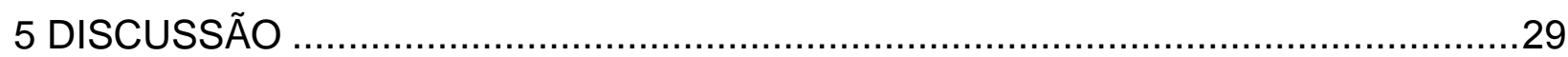

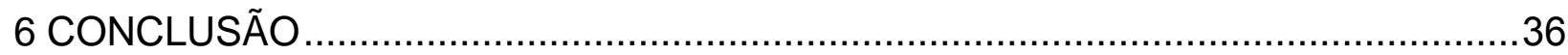

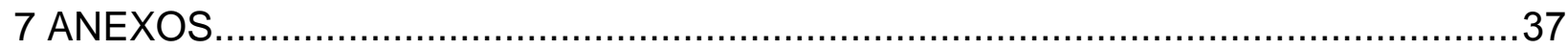

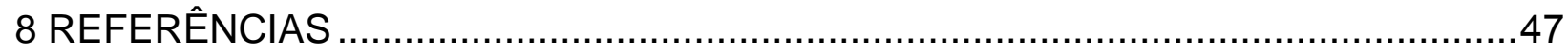

Abstract

Apêndices 


\section{Lista de tabelas}

Tabela 1. Características pessoais e dados antropométricos dos participantes ...........20

Tabela 2. Características da doença dos participantes......................................... 21

Tabela 3. Dados do questionário WOMAC ...................................................... 22

Tabela 4. Dados do questionário de qualidade de vida EQ-5D-3L .......................... 22

Tabela 5. Dados da Escala Visual Analógica de Dor .......................................... 23

Tabela 6. Dados do Teste Timed Up and Go................................................ 23

Tabela 7. Dados da avaliação de força isométrica........................................... 24

Tabela 8. Dados do teste de força isocinética................................................ 24

Tabela 9. Dados da avaliação do trabalho isocinético ......................................... 25

Tabela 10. Dados do teste incremental.................................................... 26

Tabela 11. Dados da Escala de Borg durante o teste incremental ..........................26

Tabela 12. Dados do teste de uma repetição máxima .........................................27

Tabela 13. Associação entre variação no WOMAC padronizado e características dos

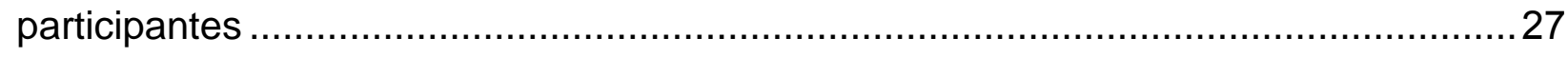




\section{Lista de abreviaturas}

1RM Uma Repetição Máxima

ACSM American College of Sports Medicine

$\mathrm{CL} \quad$ Lado contralateral

CVM Contração voluntária máxima

EQ-5D-3L EuroQol EQ-5D-3L

EVA Escala Visual Analógica

F/E Razão flexores/extensores

ICn Índice Contrátil Isométrico normalizado

IMC Índice de massa corporal

OARSI Osteoarthritis Research Society Internacional

PTC Pico de torque concêntrico isocinético

PTCE Pico de torque concêntrico dos extensores

PTCF Pico de torque concêntrico dos flexores

PTCn Pico de torque concêntrico isocinético normalizado

PTI Pico de torque isométrico

PTIE Pico de torque isométrico em extensão

PTIF Pico de torque isométrico em flexão

PTIn Pico de torque isométrico normalizado

TUG Timed Up and Go

Wn Trabalho isocinético

WOMAC Western Ontario e McMaster Universities 


\section{Resumo}

Introdução: A osteoartrose, vinculada principalmente ao envelhecimento, causa degeneração da cartilagem articular, dor articular e consequentemente inaptidão locomotora, sendo um problema importante de saúde pública. Não existem medicamentos capazes de curar, reverter ou deter a progressão da osteoartrose. Exercício e atividade física em combinação com a educação do paciente têm mostrado resultados eficientes como primeiro tratamento para reduzir a dor no joelho e melhorar a função física e, consequentemente, a qualidade de vida. Objetivos: Avaliar o tratamento conservador simplificado para três grupos musculares em pacientes portadores de osteoartrose de joelho em relação à dor, funcionalidade, força muscular e qualidade de vida. Métodos: Estudo de coorte prospectivo composto de participantes com osteoartrose de joelho, de ambos os sexos, com idade entre 45 e 65 anos. Os participantes realizaram o protocolo simplificado de exercícios para três grupos musculares durante oito semanas, com três sessões/semana que consistiu na realização de três exercícios de resistência: leg press, extensão e flexão de joelho. Os desfechos foram avaliados pela escala funcional para osteoartrose - Western Ontario MacMaster University, escala de qualidade de vida, Escala Visual Analógica de Dor, teste funcional - Timed Up and Go e avaliações de força muscular. Os desfechos foram coletados nos momentos pré e pós-protocolo de reabilitação. Resultados: Quarenta e sete participantes, 30 do sexo feminino (63,8\%), com média de idade de 55,4 anos, índice de massa corporal de $29,3 \mathrm{~kg} / \mathrm{m}^{2}$, índice de Kellgren e Lawrence $2(68,1 \%)$ e 3 $(31,9 \%)$ finalizaram o estudo. Os participantes apresentaram melhora na dor pela Escala Visual Analógica, rigidez e função pela escala Western Ontario MacMaster University, melhora na percepção da dor pela escala Escala Visual Analógica de Dor, nos escores de estado de saúde pela escala de qualidade de vida e a habilidade de mobilidade pelo Timed Up and Go. A avaliação de força isométrica dos músculos extensores e flexores dos membros inferiores apresentou aumento no pico de torque após o término do protocolo. Na avaliação do índice contrátil de força isométrica houve aumento significativo em flexão em ambos os lados e em extensão no lado não acometido pela osteoartrose. Na avaliação do pico de torque da força isocinética e trabalho houve aumento significativo na flexão de ambos os lados. Não observamos evidências de associação entre a variação maior ou igual a 8,8\% no escore Western 
Ontario MacMaster University, o qual foi padronizado como indicador de melhora clínica, e as variáveis sexo, idade, Índice de Massa corporal, grau de artrose e escores escala de qualidade de vida e Escala Visual Analógica de Dor, sugerindo que o protocolo pode ser indicado como tratamento para indivíduos de ambos os sexos e com a faixa etária entre 45 e 65 anos. Conclusões: $O$ tratamento conservador simplificado para fortalecimento de três grupos musculares para pacientes portadores de osteoartrose de joelho foi efetivo na melhora da dor, funcionalidade, força muscular e qualidade de vida.

Identificador ClinicalTrials.gov: NCT 02964624

Descritores: Osteoartrite; Terapia por exercício; Medição da dor; Qualidade de vida; Força muscular 


\section{INTRODUÇÃo}

A osteoartrose é uma doença crônica com diferentes etiologias, mas com resultados biológicos, morfológicos e clínicos semelhantes, afetando a cartilagem articular, o osso subcondral, a sinóvia, a cápsula e os ligamentos; a cartilagem degenera com fibrilação, fissuras, ulceração e perda total da espessura da superfície articular. $^{(1)}$ É um distúrbio que envolve articulações, caracterizado por estresse celular e degradação da matriz extracelular iniciado por micro e macro lesões que ativam respostas de reparo, incluindo vias pró-inflamatórias da imunidade inata. A doença manifesta-se inicialmente como um desarranjo molecular, seguido de distúrbios anatômicos e/ou fisiológicos os quais são caracterizados pela degradação da cartilagem, remodelação óssea, formação de osteófitos, inflamação articular e perda da função articular normal, desenvolvendo sintomas clínicos. ${ }^{(2)}$ É caracterizada principalmente por degeneração da cartilagem e alterações ósseas subjacentes ${ }^{(3)} \mathrm{e}$ não decorre apenas do processo de envelhecimento, mas também é determinada por outros fatores de risco, como obesidade e lesões traumáticas, os quais favorecem a instalação da doença. ${ }^{(4)}$ Portanto a etiologia da osteoartrose de joelho é multifatorial, envolvendo fatores como envelhecimento, obesidade, hereditariedade, sexo e sobrecarga mecânica. ${ }^{(5)}$

A osteoartrose é o tipo mais comum de artrite em todo o mundo e está associada à morbidade, com aumento significativo da prevalência em decorrência do envelhecimento da população. Dor e rigidez nas articulações, redução na participação em atividades remuneradas e má qualidade de vida são comuns em indivíduos com osteoartrose. ${ }^{(6)}$ É considerada a principal responsável pelo dispêndio econômico devido às ausências no trabalho decorrente do agravamento do quadro doloroso e deterioração da função. Com o envelhecimento da população e aumento da obesidade mundial estima-se que o ônus da osteoartrose seja um grande problema para os sistemas de saúde globalmente..$^{(7-9)}$

Estima-se que entre $40 \%$ a $80 \%$ das pessoas com alterações radiográficas terão osteoartrose sintomática. A osteoartrose sintomática do joelho é altamente prevalente entre os idosos do mundo (10\% a $30 \%$ ). Uma em cada quatro pessoas com mais de 55 anos são afetadas por osteoartrose sintomática de joelho, tornando-a a principal causa de dor e incapacidade em adultos. ${ }^{(10)}$ 
A prevalência da osteoartrose excede a prevalência autorrelatada de outros problemas médicos comuns, como hipertensão, diabetes mellitus, doença cardíaca isquêmica e tuberculose. ${ }^{(11)}$ No Brasil, há poucos estudos demográficos da doença, mas estudo de 2004, descreve que a incidência de osteoartrose no país é de $4,14 \% .{ }^{(12)} \mathrm{A}$ osteoartrose é considerada uma entre as dez doenças mais incapacitantes nos países desenvolvidos. Estimativas mundiais são de que 9,6\% dos homens e 18,0\% das mulheres com mais de 60 anos têm osteoartrose sintomática e que $80 \%$ das pessoas com osteoartrose terão limitações de movimento e $25 \%$ não poderão realizar suas principais atividades de vida diária. ${ }^{(13)}$

As terapias biológicas com células-tronco, tanezumab e NF-KB (fator nuclear Kappa B) têm sido o foco de novos estudos e estão cada vez mais sendo sugeridas como alternativas para o tratamento da osteoartrose. Embora estudos usando essas terapias mostrem uma grande promessa para pacientes com OA leve a moderada do joelho, eles se concentraram em outros tratamentos e prevenção, que são a base para o tratamento da OA. Portanto, são necessárias mais pesquisas sobre terapias biológicas para a $\mathrm{OA}$ do joelho para avaliar os riscos e benefícios e, especialmente, para entender o mecanismo de ação e os resultados a longo prazo. ${ }^{(14)}$

Os tratamentos atuais para osteoartrose são direcionados para alívio da dor e redução da incapacidade funcional secundária incluindo a utilização de drogas como analgésicos simples, medicamentos anti-inflamatórios não esteroides e injeções intra-articulares, terapias físicas, fortalecimento muscular e exercícios, uso de dispositivos auxiliares, educação, perda de peso, apoio social e intervenções cirúrgicas quando necessário. Há evidências de que os exercícios de fortalecimento do quadríceps são benéficos no controle da osteoartrose e também em longo prazo, para a dor e a função do joelho. ${ }^{(15)}$

Exercício, atividade física e combinação com a educação do paciente têm mostrado resultados eficientes como primeiro tratamento para reduzir a dor no joelho e melhorar a função física e, consequentemente, a qualidade de vida. Revisões sistemáticas evidenciam que exercício e atividade física são intervenções importantes e seguras na reabilitação de idosos, melhorando a dor e função no joelho. Em resumo, a terapia baseada na prática de exercícios é considerada um tratamento eficaz, seguro e de baixo custo disponível para a osteoartrose. ${ }^{(16-18)}$

Com o envelhecimento da população mundial, haverá um grande aumento no número de pessoas com osteoartrose que necessitam de serviços e 
cuidados de saúde. Trabalhos preventivos de baixo custo se tornam cada vez mais necessários para auxiliar na redução da progressão da doença. $O$ desenvolvimento de estratégias preventivas para osteoartrose visando o ganho de força muscular e alongamento muscular através de exercícios simplificados tornam-se cada vez mais importantes.

Existem evidências consistentes de que diferentes modalidades de exercício físico têm um efeito benéfico na melhora da dor, função articular e qualidade de vida em pacientes com osteoartrose do joelho. A terapia baseada em exercícios com treinamento de força é considerada um tratamento essencial na osteoartrose do joelho e é recomendada em diretrizes internacionais, embora o volume ideal de exercício ("dose") não seja quantificado e a prescrição eficaz de exercícios ainda não tenha sido estabelecida. ${ }^{(19)} \mathrm{O}$ exercício é eficaz e clinicamente útil na redução da dor, embora alguns questionamentos sobre exercícios em pacientes com OA de joelho parecem ser mais importantes, como: 'que tipo de exercícios para qual tipo de paciente é mais eficaz?'; 'qual é o efeito adicional do exercício em uma combinação de tratamentos?', 'o exercício reduz ou adia a cirurgia total do joelho?' ou 'qual é a melhor estratégia para implementar 0 tratamento com exercícios nos cuidados com osteoartrose? $?^{\prime(20)}$

Uma vez que a osteoartrose do joelho é considerada um problema de saúde pública, seria desejável uma abordagem menos dispendiosa. Em virtude disso, o tratamento conservador simplificado com exercícios para três grupos musculares de membros inferiores pode melhorar a dor e a funcionalidade de pacientes portadores de osteoartrose de joelho.

\subsection{Objetivo}

1. Avaliar o tratamento conservador simplificado para pacientes portadores de osteoartrose de joelho em relação à dor, funcionalidade, força muscular e qualidade de vida. 


\section{REVISÃO DA LITERATURA}

A osteoartrose do joelho é um distúrbio osteomuscular comum e doloroso para o qual não há cura; portanto a necessidade de gerenciamento do déficit de força muscular e propriocepção são de suma importância para atenuar declínios na função e qualidade de vida. ${ }^{(21)}$ Intervenções conservadoras e não farmacológicas desempenham um papel crítico na gestão dos sintomas e incapacidade da osteoartrose. O exercício e educação do paciente no contexto da autogestão continuam sendo intervenções efetivas para a osteoartrose, sendo necessário enfatizar o tipo e a dosagem do exercício. ${ }^{(22)}$

Exercícios terapêuticos são usados para melhorar déficits fisiológicos como movimento articular reduzido, fraqueza muscular, déficit de equilíbrio e propriocepção. ${ }^{(23)}$ Tratamentos considerados apropriados e seguros para a maioria dos pacientes com osteoartrose do joelho são programas de exercícios estruturados em terra, combinados com controle de peso corporal e exercícios considerados mentecorpo, como Tai Chi e Yoga. ${ }^{(24)}$

Análise de revisão sistemática relacionada à aplicação da fisioterapia como tratamento para a osteoartrose do joelho constatou que, dentre todas as variáveis analisadas, apenas exercício e redução de peso corporal apresentaram evidências de promoção de melhora da dor e função. ${ }^{(25)}$ No entanto, não está claro qual exercício é considerado mais eficaz para o tratamento da osteoartrose em relação aos diferentes desfechos obtidos. Estudo comparando diferentes tipos de exercícios, como aeróbico (caminhada, ciclismo), exercícios de flexibilidade, treinamento neuromotor, treinamento proprioceptivo; treinamento de resistência; mente-corpo (Taichi, Yoga), observou que, para melhorar a função o exercício mente-corpo foi o mais adequado, seguido de exercícios de força e flexibilidade e por último os exercícios aeróbicos. Os exercícios individuais apresentaram consistentemente melhores resultados do que os exercícios em grupo. ${ }^{(26)}$

Outra revisão sistemática, analisando 54 estudos clínicos, concluiu que os programas de exercícios terapêuticos baseados em terra resultaram em aumento do benefício médio imediato como tratamento para dor no joelho, função física e qualidade de vida. Ainda, o estudo apresenta evidências de alta qualidade indicando que o exercício terapêutico terrestre proporciona benefícios de curto prazo, em relação a dor no joelho, os quais são mantidos entre dois a seis meses após a interrupção do 
tratamento formal, enquanto que evidências de qualidade moderada mostram melhora na função física entre pessoas com osteoartrose do joelho. A magnitude do efeito do tratamento foi considerada moderada (imediata) a pequena (dois a seis meses), mas comparável ao uso de anti-inflamatórios não esteroidais. ${ }^{(27)}$

A combinação de exercício e autocuidado auxilia idosos com osteoartrose a gerenciar suas comorbidades. Estudo descreve um programa com esta combinação, semelhante a um circuito dentro de uma academia pública, onde os participantes eram desafiados a aumentar a complexidade do circuito de acordo com a capacidade e familiarização do circuito. Com sessões de duas horas e meia e frequência de duas vezes por semana, durante seis semanas, o estudo concluiu que é possível utilizar este formato de programa para idosos com osteoartrose, demonstrando que pessoas mais velhas podem frequentar academia com apoio e desfrutar de atividades em grupo, o que as ajuda a gerenciar sua doença. ${ }^{(28)}$

A revisão de ensaios clínicos randomizados sobre a eficácia dos programas de exercícios para osteoartrose de joelho e quadril, concluiu que há fortes evidências da eficácia de programas de exercícios aeróbicos e de fortalecimento muscular, terrestres e aquáticos, para a redução da dor e melhora da função física em indivíduos com osteoartrose do joelho leve a moderada. O estudo também ressalta que novas pesquisas são necessárias para evidenciar quais modalidades e tipos de atividade física são mais eficazes para pacientes com osteoartrose e a variabilidade dos resultados de acordo com as características individuais do paciente. ${ }^{(29)}$

Exercícios terrestres são altamente recomendados para todas as pessoas com osteoartrose do joelho para melhorar a dor e a função, independentemente da idade, gravidade estrutural da doença, estado funcional ou níveis de dor. ${ }^{(30)}$ Exercícios terapêuticos para osteoartrose são considerados uma abordagem com eficácia comprovada. No entanto, as diferentes formas de doença, a falta de consenso estabelecido e o sistema de educação do paciente limitam o uso generalizado de exercícios terapêuticos na prática clínica. Os principais exercícios utilizados em pacientes com osteoartrose são exercícios de alongamento, exercícios de amplitude de movimento, exercícios analíticos para fortalecimento muscular (isométrico e isotônico) e exercícios aeróbicos (caminhada, ciclismo, natação). Os programas de exercícios recomendados devem ser individualizados de acordo com a idade do paciente, gravidade da osteoartrose e presença de doenças concomitantes. ${ }^{(31,32)}$ 
Uma variedade de exercícios tem sido proposta na literatura como opção de tratamento para osteoartrose do joelho, incluindo exercícios aeróbicos, como andar de bicicleta ou a pé, bem como alguns exercícios direcionados, como fortalecimento de músculos específicos e alguns exercícios visando a flexibilidade. A maioria dos estudos que investigam os efeitos do fortalecimento muscular em pacientes com osteoartrose do joelho se concentram principalmente no quadríceps. ${ }^{(33)}$

Revisão sistemática e metanálise de oito estudos clínicos sintetizou que os efeitos de exercícios de fortalecimento em terra de várias modalidades e intensidades visavam determinar, em pessoas com osteoartrose do joelho, a eficácia da adição de exercícios de fortalecimento do quadril aos exercícios do quadríceps e o tipo de exercício de fortalecimento do quadril com a maior evidência de melhora da dor, função e qualidade de vida e concluiu que a caminhada melhorou após a adição do fortalecimento do quadril ao fortalecimento do quadríceps em pessoas com osteoartrose de joelho resultando em melhora na dor e na função relatadas pelo paciente. $^{(34)}$

Outro estudo de revisão evidenciou que o tratamento central da osteoartrose deve conter a prática de exercícios realizados isoladamente ou combinados, ou seja, a combinação de exercícios terrestre e aquático, exercício mentecorpo (Hatha yoga, Tai chi), exercício de fortalecimento, exercício aeróbico acompanhados de controle de peso corporal, autogestão e educação. ${ }^{(35)}$

O exercício resistido é definido como qualquer programa de exercícios no qual ocorre acréscimo gradual de carga, respeitando a dor e os limites do praticante, considerando a seleção dos exercícios, a resistência, número de séries e repetições, a velocidade da execução, o tempo de repouso entre as séries e a frequência. ${ }^{(36)}$ O American College of Sports Medicine (ACSM) define modelos de progressão no treinamento resistido para adultos saudáveis, que são: ações musculares concêntricas e excêntricas, sequência do programa de força com exercícios de grandes grupos musculares antes dos exercícios de pequenos grupos musculares, exercícios de múltiplas articulações antes dos exercícios de uma articulação e maior intensidade antes dos exercícios de menor intensidade. As recomendações para a prática de exercícios resistidos para iniciantes segundo ACSM são:

- Frequência: cada grupo muscular principal deve ser treinado em 23 vezes por semana; 
- Intensidade: $60 \%$ a $70 \%$ do Teste de Uma Repetição Máxima (1RM) (intensidade moderada a forte) para iniciantes e intermediários, para melhorar a força;

- Tempo: nenhuma duração específica do treinamento foi identificada para eficácia;

- Tipo: recomenda-se exercícios de resistência envolvendo cada grupo muscular principal. Uma variedade de equipamentos e/ou peso corporal pode ser usada para realizar esses exercícios;

- Repetições: recomenda-se de 8 a 12 repetições para melhorar a força na maioria dos adultos;

- Séries: duas a quatro séries são recomendadas para adultos para ganho de força muscular;

- Repouso: intervalos de descanso de 2 a 3 minutos entre cada conjunto de repetições são efetivos; com descanso mínimo entre sessões de 48hs para cada grupo muscular.

- Progressão: Recomenda-se uma progressão gradual para maiores resistências, mais repetições por série e/ou frequência crescente. ${ }^{(36,37)}$

Assim, considerando a ausência de consenso sobre o melhor tipo de exercício no tratamento de osteoartrose e as recomendações da ACSM, o presente estudo avaliou os resultados da prática de um protocolo simplificado de exercícios resistidos de três grupos musculares dos membros inferiores em pacientes com osteoartrose de joelho. 


\section{MÉTODOS}

\subsection{Delineamento do estudo}

Trata-se de uma coorte prospectiva.

\subsection{População estudada}

Foram incluídos no estudo 47 indivíduos com osteoartrose de joelho leve a moderada de ambos os sexos com idade entre 45 e 65 anos.

\subsection{Recrutamento}

Os indivíduos foram recrutados por meio de publicações em mídias sociais do Hospital Israelita Albert Einstein (HIAE) no período de janeiro de 2017 a janeiro 2019 (Figura 1). Os participantes foram atendidos no Programa de Ortopedia do HIAE entre janeiro de 2017 e março de 2019. A figura 1 ilustra o fluxo para o recrutamento dos participantes da pesquisa. 


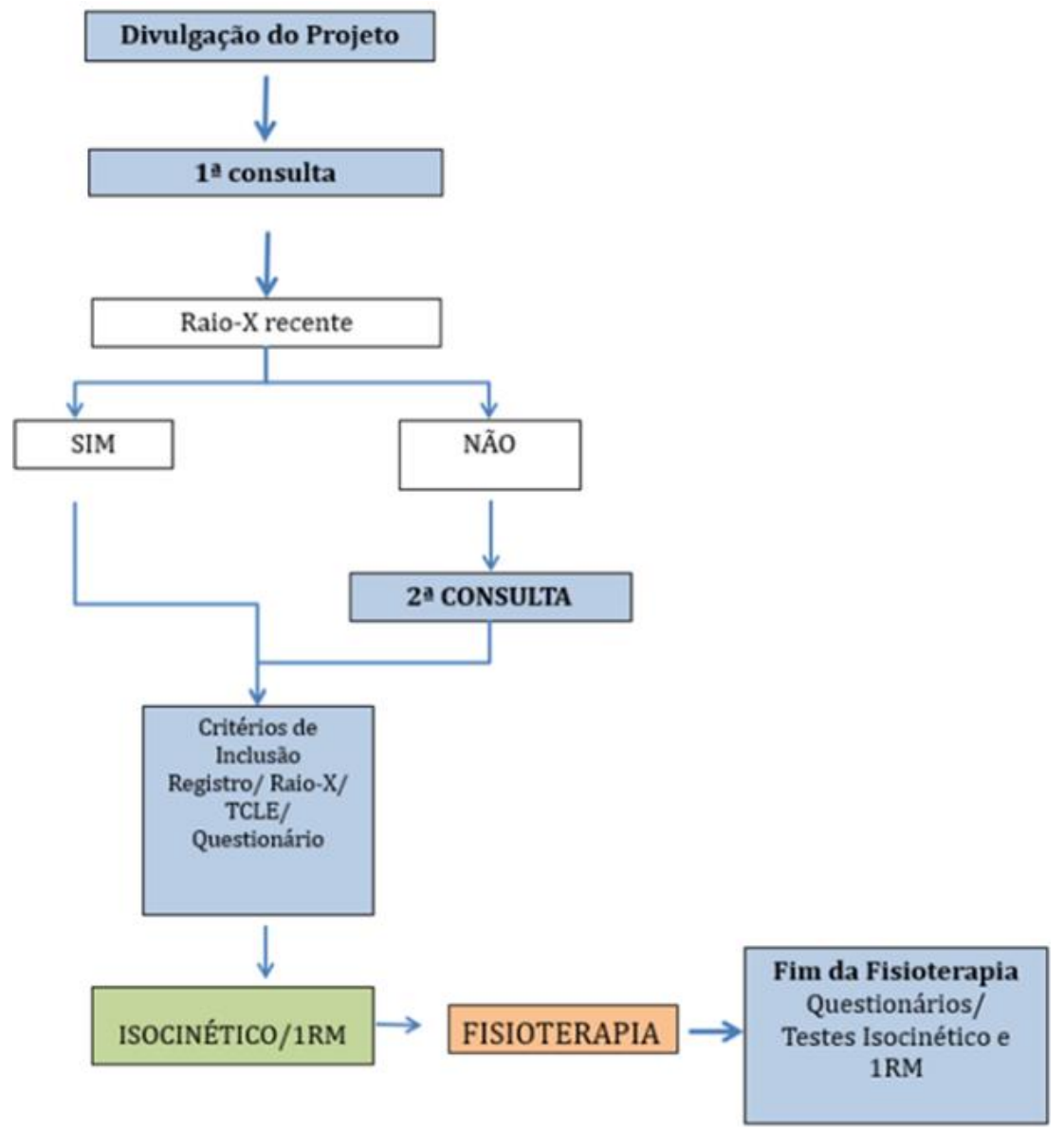

Figura 1. Fluxograma do projeto

Este estudo foi registrado e aprovado pelo Sistema Gerenciador de Projetos de Pesquisa (SGPP) número: 2640-16 e pelo Comitê de Ética em Pesquisa (CEP) do HIAE com o Certificado de Apresentação de Apreciação Ética (CAAE) n: 5505.3616.1.0000.0071. O estudo também foi registrado na plataforma ClinicalTrials.gov (NCT 02964624). O estudo recebeu financiamento da Fundação de Amparo à Pesquisa do Estado de São Paulo em edital em parceria com The Ohio State University (FAPESP/OSU: 2015/50274-5).

\subsection{Descrição da amostra}

Os participantes foram informados textual e verbalmente sobre os seus direitos, benefícios e possíveis riscos, objetivos e metodologias do estudo. $O$ Termo de Consentimento Livre e Esclarecido (TCLE) (Anexo 1) foi assinado após concordância da participação. $O$ estudo foi realizado com participantes que preencheram os critérios listados abaixo. 


\subsubsection{Critérios de inclusão}

Os critérios de inclusão foram:

- Homens e mulheres entre 45 e 65 anos com osteoartrose de joelho de acordo com os critérios clínicos do Colégio Americano de Reumatologia; (35)

- Osteoartrose grau 2 e 3 (leve e moderado) de acordo com a classificação radiográfica de Kellgren e Lawrence.

\subsubsection{Critérios de exclusão}

Os critérios de exclusão foram:

- Osteoartrose avançada do joelho conforme a classificação de Kellgren e Lawrence (grau 4);

- Presença de afecção ortopédica grave nos membros inferiores ou na coluna;

-Presença de doença cardíaca coronariana ou câncer autorrelatada; - Índice de massa corporal (IMC) > 35;

- Programação de cirurgia ortopédica;

- Praticante(s) de atividade física moderada acima de duas vezes por semana;

- Ter realizado artroplastia do joelho ou osteotomia tibial alta;

- Perder mais de duas sessões de fisioterapia durante o estudo ou duas sessões consecutivas;

- Presença de osteoartrose femoropatelar.

\subsection{Avaliações}

Os participantes foram submetidos às seguintes avaliações:

- Preencheram a ficha sociodemográfica (Apêndice 1)

- Consulta médica com médicos ortopedistas que avaliaram inicialmente os participantes de acordo com os crité2ios de inclusão. Foram solicitadas radiografias de joelho com carga na incidência coronal (anteroposterior) e lateral a $30^{\circ}$ 
de flexão para avaliar o espaço articular, conforme classificação de Kellgren e Lawrence. A classificação de 0 a 4 , onde 0 indica ausência de alterações de osteoartrose na radiografia, 1 indica grau duvidoso, grau 2 indica mínima presença de osteoartrose, grau 3 indica osteoartrose moderada e grau 4 indica osteoartrose severa. ${ }^{(38)}$ A avaliação foi realizada por dois médicos ortopedistas independentes.

- Profissional de Educação Física realizou as avaliações de força muscular no dinamômetro isocinético (início e final do programa).

- Fisioterapeuta: realizou a coleta de dados e aplicou os questionários e realizou os testes Timed Up and Go (TUG) (início e final do programa), Teste Incremental e Teste de 1RM (início, meio e final do programa).

\subsection{Medidas de desfecho}

\subsubsection{Instrumento de avaliação primária}

\subsubsection{Western Ontario e McMaster Universities}

Os participantes responderam o questionário Western Ontario e McMaster Universities (WOMAC) (Anexo 2) para a avaliação da dor, rigidez e função na osteoartrose dos membros inferiores durante as atividades diárias no início e após 8 semanas (final do protocolo de fisioterapia); que contém 5 perguntas para dor, 2 perguntas para rigidez e 17 perguntas para atividades da vida diária. A escala WOMAC possui 5 itens (nenhuma $=0$, leve $=1$, moderada $=2$, grave $=3$, extrema $=4$ ) resultando em escore de dor ( 0 a 20), escore de rigidez ( 0 a 8) e escore de limitação de atividade $(0$ a 68$)$. A pontuação total do WOMAC apresenta variação de 0 a 96 pontos com pontuações mais altas indicando pior função. ${ }^{(39)}$

\subsubsection{Instrumentos de avaliação secundária}

\subsubsection{Questionário relacionado com a saúde e qualidade de vida}

O Questionário relacionado com a saúde e qualidade de vida EuroQoL (EQ-5D-3L) (Anexo 3) é utilizado como forma descritiva de mensuração da 
qualidade de vida, dividida em cinco diferentes dimensões: mobilidade, autocuidado, atividades usuais, dor/desconforto, ansiedade e depressão com três níveis de resposta, com variação entre "sem problemas, problemas moderados e problemas extremos". Há um código para pontuação e após o cálculo é gerado um número até no máximo um (1) ponto. Quanto mais perto de um (1), melhor a qualidade de vida e quanto mais perto do zero (0), pior qualidade de vida. ${ }^{(40)}$ O questionário foi aplicado antes do início do protocolo e após 8 semanas (final do protocolo de fisioterapia).

\subsubsection{Escala Visual Analógica da dor}

A Escala Visual Analógica (EVA) (Anexo 4) da dor é uma medida autorrelatada da intensidade da dor unidimensional, que tem sido amplamente utilizado em diversas populações de adultos, incluindo aqueles com as doenças reumáticas. ${ }^{(41)}$ O questionário foi aplicado antes do início do protocolo e após 8 semanas (final do protocolo de fisioterapia).

\subsubsection{Teste Timed Up and Go}

O Teste TUG é baseado do desempenho da função física para pessoas com osteoartrose, complementar às medidas de autorrelato como os questionários, segundo a Osteoarthritis Research Society Internacional (OARSI). O teste consiste em medir o tempo em segundos para uma pessoa se levantar da posição sentada a partir de uma cadeira padrão com braços (altura de 65 centímetros), caminhar 3 metros, virar, caminhar de volta para a cadeira e sentar-se. ${ }^{(42)} \mathrm{O}$ resultado foi obtido da média de três tomadas de tempo virando para a esquerda e três para a direita. O teste foi aplicado antes do início do protocolo e após 8 semanas (final do protocolo de fisioterapia).

\subsubsection{Avaliação de força isométrica e isocinética}

Ambos os testes, isométrico e isocinético, foram realizados em um dinamômetro isocinético (Biodex System 4, Shirley, NY), antes do início do protocolo e 
após 8 semanas (no final do protocolo de reabilitação). Durante os testes os participantes estavam seguramente fixos à cadeira e ao braço de alavanca do dinamômetro (Figura 2). Um estímulo verbal constante e uniforme foi aplicado pelo examinador durante o teste para todos os participantes: "atenção, preparar, vai, força, força...", assim como feedback visual do monitor do computador do dinamômetro.

O eixo de rotação do dinamômetro e o eixo anatômico do joelho (epicôndilo lateral do fêmur) foram alinhados para a realização do teste. O braço de alavanca do dinamômetro foi fixado na região distal da perna $(5 \mathrm{~cm}$ acima do maléolo medial), permitindo uma completa amplitude de movimento do tornozelo. A força isométrica foi mensurada pelo pico de torque isométrico (PTI) obtido durante uma contração voluntária máxima (CVM) em extensão (PTIE), e em flexão (PTIF) do joelho. Para a CVM dos extensores, o ângulo entre coxa e perna será de $75^{\circ}\left(0^{\circ}=\right.$ extensão total) e para os flexores de $40^{\circ}\left(0^{\circ}=\right.$ extensão total). Depois da familiarização com 0 protocolo, duas contrações voluntárias máximas de cinco segundos foram solicitadas e realizadas para cada movimento articular, com 3 minutos de intervalo entre tentativas e o maior valor entre estas foi considerado como PTIE e PTIF. ${ }^{(43)}$

A força isocinética foi mensurada pelo pico de torque concêntrico isocinético (PTC) durante uma CVM concêntrica a $60^{\circ} . \mathrm{s}^{-1}$ dos extensores (PTCE) e flexores (PTCF) do joelho e do Trabalho isocinético (Wn). A amplitude de movimento angular de $90^{\circ}\left(0^{\circ}=\right.$ extensão total). Depois da familiarização com o protocolo, foram solicitadas e realizadas cinco contrações voluntárias máximas consecutivas de extensão e flexão do joelho. O maior valor entre tentativas foi considerado como PTCE e PTCF, sendo estes utilizados para determinar a razão de equilíbrio de força entre isquiotibiais (flexores do joelho) e quadríceps (extensores do joelho) (F/E). Os dados obtidos foram normalizados pelo peso corporal do participante, mensurado antes da sessão de cada avaliação, reduzindo assim a variabilidade dos dados em relação às diferenças antropométricas entre homens e mulheres. ${ }^{(44)}$ 


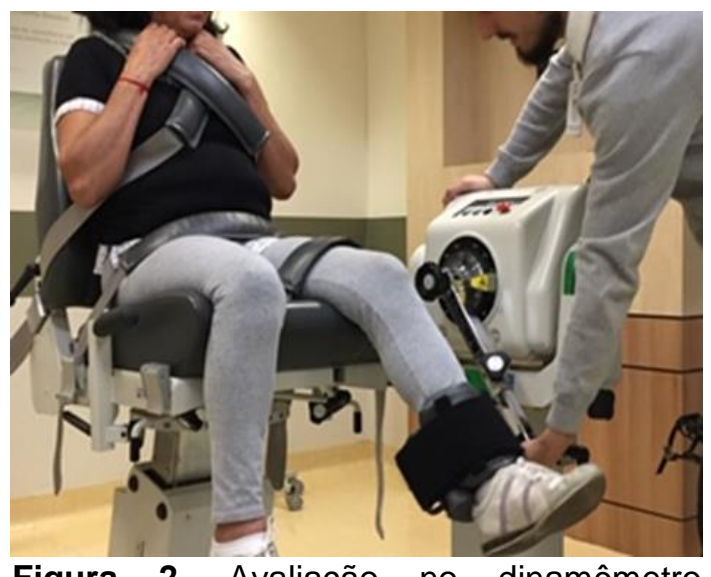

Figura 2. Avaliação no dinamômetro isocinético

\subsubsection{Teste incremental}

Para iniciar o teste o participante era posicionado no ciclo ergômetro com coluna apoiada no encosto do banco e pés apoiados nos pedais a uma distância que possibilitasse a extensão completa dos joelhos durante a execução do teste. Durante o teste de familiarização, a distância do assento do ciclo ergômetro foi ajustada para cada participante. A configuração individual do ciclo ergômetro foi registrada para garantir que a mesma fosse utilizada durante a realização do protocolo de reabilitação e no teste final. Após aquecer em cadência livre por 5 minutos a intensidade foi aumentada a cada 3 minutos, até que o registro participante atingisse a pontuação entre 11 e 13 na escala de Borg, pontuação considerada de intensidade moderada. $^{(45)}$

\subsubsection{Teste de uma repetição máxima}

O teste de força muscular foi realizado através do cálculo de 1RM que mostra o máximo de carga sustentada durante uma repetição. O teste iniciava com aquecimento de 5 a 10 repetições com estimativa moderada de carga $(40-60 \%$ de 1RM). Após 1 minuto de descanso, 3 a 5 repetições foram realizadas com maior carga (60-80\% de 1RM). Então, uma tentativa de 1RM estimado foi aplicada. Se o participante falhar para levantar a carga por duas repetições o teste era abortado, caso contrário depois de 5 minutos de descanso, a carga era aumentada e o teste realizado 
novamente. Apenas cinco tentativas foram permitidas por dia para garantir a confiança do teste. ${ }^{(36,37)}$

Foram realizadas as seguintes avalições de força muscular através do cálculo de 1RM:

- Cadeira extensora: o participante era posicionado sentado no aparelho com a coluna apoiada no encosto com joelhos flexionados a $90^{\circ}$; o avaliador orientava como o teste seria realizado, esclarecendo a necessidade de realizar a extensão completa dos joelhos sem realizar desvios em varo ou valgo; em seguida era solicitado ao participante que realizasse 5 repetições sem carga para a verificação do entendimento do exercício antes da aplicação do teste (Figura 3).

- Cadeira flexora: o participante repetia o posicionamento do teste anterior com o joelho partindo da extensão completa para a flexão de $90^{\circ}$; as solicitações do avaliador eram as mesmas do teste anterior (Figura 3).

- Leg press: o participante era posicionado com coluna apoiada no encosto do aparelho, quadril e joelhos flexionados a $90^{\circ}$ e pés apoiados na plataforma. O avaliador orientava o participante a realizar a extensão completa de quadril e joelhos (evitando a hiperextensão dos joelhos), o que levaria ao deslizamento posterior da cadeira (Figura 3).

\subsection{Protocolo de reabilitação}

Os participantes foram submetidos a um programa de fisioterapia para fortalecimento muscular simplificado de três grandes grupos musculares, realizado em três equipamentos de musculação para músculo quadríceps (cadeira extensora), músculos isquiotibiais (cadeira flexora) e músculos glúteos, isquiotibiais e quadríceps associados (leg press) (Figura 3). As sessões foram realizadas 3 vezes por semana, durante oito semanas (totalizando 24 sessões).

Cada sessão teve início com a avaliação da dor do participante através da escala EVA; em caso de dor maior do que quatro (4) nesta escala, um protocolo de analgesia contendo ultrassom, laser ou eletro analgesia foi aplicado. A liberação para execução do protocolo ocorreria se, após o protocolo de analgesia, o participante reportasse um nível de dor inferior a quatro (4) na escala EVA.

Sequência do programa de exercícios: 
- Exercício de aquecimento em bicicleta ergométrica por 5 minutos em cadência livre, seguido de 10 minutos a $90 \%$ da intensidade obtida durante o teste incremental.

- Execução dos exercícios de fortalecimento muscular com quatro conjuntos de 8 a 12 repetições na cadeira extensora, cadeira flexora e leg press (Figura 3) utilizando ambos os membros inferiores (o participante foi orientado a aplicar força igualmente em ambos os membros inferiores durante a execução dos exercícios). A carga utilizada foi de $70 \%$ da carga obtida no teste de 1RM, com intervalo de um minuto entre as séries e exercícios. Na décima terceira sessão o teste de 1RM foi aplicado novamente para adequação da progressão da carga. ${ }^{(36)}$

- Exercícios de alongamento muscular para membros inferiores executados no final da sessão; a dor foi avaliada através da EVA. Os exercícios de alongamento foram orientados em ortostatismo para que o próprio participante realizasse: para o alongamento do músculo quadríceps, o joelho era flexionado e próprio participante segurava seu tornozelo. $\mathrm{O}$ alongamento dos músculos isquiotibiais era realizado com um pé apoiado no solo e o outro apoiado em um espaldar (degrau) mantendo ambos os joelhos em extensão e o tronco ligeiramente inclinado para frente; para alongamento do músculo tríceps sural, utilizou-se uma rampa de alongamento ou degrau, mantendo os joelhos em extensão e o tronco inclinado para frente. Dez segundos de tensão para cada posição de alongamento. As sessões tiveram duração de 30 a 40 minutos. O desempenho do participante era registrado a cada sessão em uma Ficha de Controle de Avaliação e Tratamento (Apêndice 2).

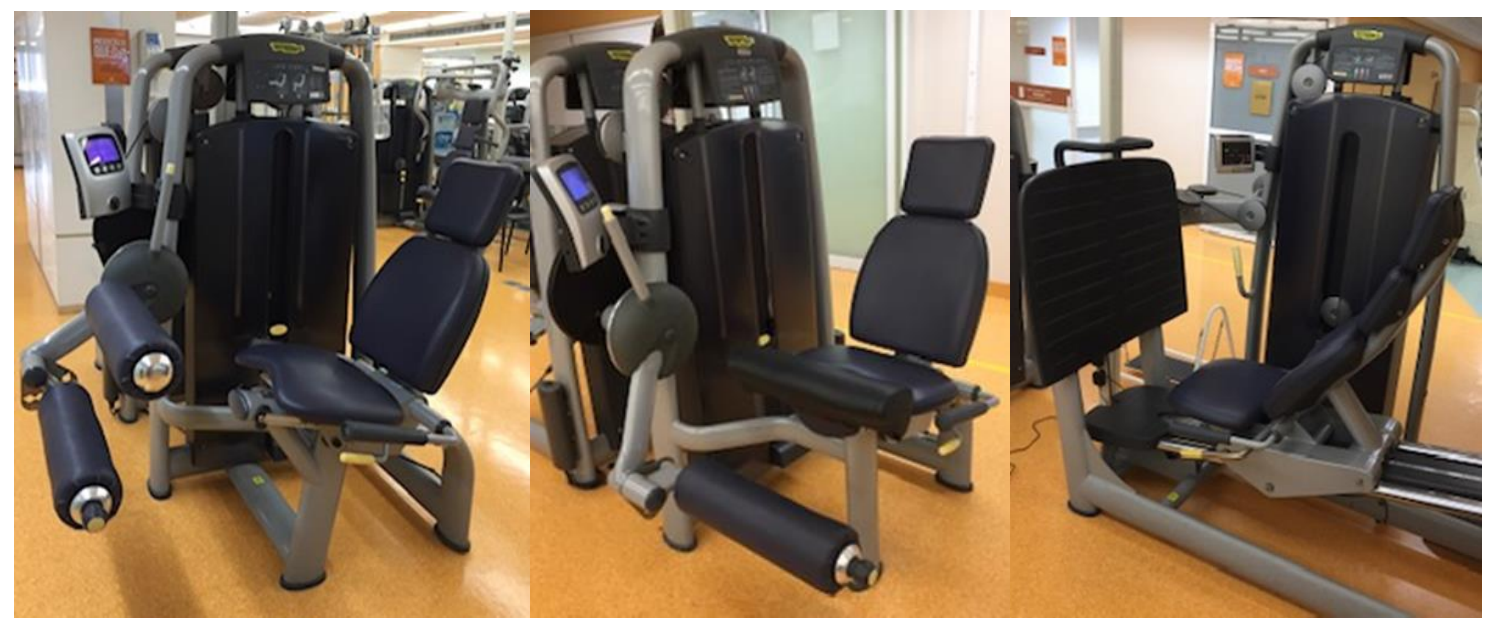

Figura 3. Cadeiras flexora, extensora e Leg press 


\subsection{Tamanho da amostra}

A estimativa do tamanho da amostra foi determinada com base na melhora da pontuação no escore da subescala da função física do WOMAC, usando o software G.Power 3.15. Com base na diferença esperada de $8,8 \%$ entre a medida de linha de base e após o tratamento de reabilitação e um desvio padrão de 22 na função física do WOMAC, seriam necessários 65 pacientes com nível de significância de 0,05 e poder estatístico de $80 \%$.

\subsection{Análise estatística}

Os dados foram descritos por meio de frequências absolutas e relativas para as variáveis categóricas e por médias, desvio padrão (DP) ou medianas e quartis, além de valores mínimos e máximos para as variáveis numéricas. As distribuições das variáveis numéricas foram estudadas por meio de histogramas e boxplots e por testes de normalidade de Shapiro-Wilk. A concordância entre as avaliações pré e pós-tratamento em relação à classificação das razões $H / Q$ (razão isquiotibiais/quadríceps) foi investigada por meio de testes de McNemar. ${ }^{(46)}$

Variações nos escores dos instrumentos de questionário de qualidade de vida EQ-5D-3L, questionário de WOMAC e EVA de dor e das medidas obtidas no Teste TUG, escore da escala de Borg e frequência cardíaca no Teste Incremental e as medidas de carga obtidas no teste de 1RM com três exercícios de resistência diferentes (leg press, extensão de joelho e flexão do joelho) foram investigadas por modelos mistos generalizados, ${ }^{(47)}$ considerando a correlação entre as medidas do participante nos diferentes momentos de avaliação (pré, intermediário na $13^{\circ}$ sessão e pós). Os modelos foram ajustados com distribuição normal ou gama, e os resultados apresentados por valores médios ajustados e intervalos de confiança de $95 \%$.

As variações no estágio alcançado pelos participantes no Teste Incremental foram investigadas por meio do teste não paramétrico de Friedman seguido de testes de comparações múltiplas com valores-p corrigidos pelo método de Bonferroni. 
Foram ajustados modelos mistos generalizados para investigar variações entre as avaliações pré e pós-reabilitação quanto às medidas obtidas nos lados com osteoartrose e contralateral nas avaliações de força isométrica e isocinética (pico de torque, impulso contrátil e trabalho). Os modelos foram ajustados com distribuição normal ou gama, considerando a correlação entre as medidas de um mesmo participante nos diferentes momentos de avaliação [(pré ou pós-reabilitação e lado com osteoartrose ou lado contralateral $(\mathrm{CL})]$. Os resultados dos modelos foram apresentados por valores médios ajustados e intervalos de confiança de $95 \%$.

Foram ajustados modelos logísticos ${ }^{(48)}$ para investigar relação entre variação de pelo menos $8,8 \%$ no escore WOMAC padronizado após o tratamento e as características basais dos pacientes, escore EQ-5D-3L, escore EVA, sexo, idade, IMC e grau de artrose. Os resultados dos modelos foram apresentados por razões de chances (RC), intervalos de confiança de $95 \%$ e valores-p. As análises foram realizadas utilizando o pacote estatístico SPSS, considerando nível de significância de $5 \%$. As análises estatísticas foram realizadas com o suporte da equipe de Estatística do Instituto Israelita de Ensino e Pesquisa. 


\section{RESULTADOS}

O recrutamento foi realizado através de três divulgações em momentos distintos nas mídias sociais (internet e intranet). A divulgação resultou no contato de 572 pessoas interessadas em participar do estudo, destas, 141 apresentaram os critérios de elegibilidade para a consulta com o médico ortopedista e, após a consulta e análise de exames de Raio-X, 65 participantes foram incluídos no estudo. Porém, 11 participantes desistiram do tratamento após a inclusão e 7 participantes foram excluídos do estudo (Figura 4).

Onze (11) participantes relataram os seguintes motivos na desistência da participação do estudo: dificuldade em manter a frequência às sessões de fisioterapia exigida no estudo por morte na família $n=2$; residir distante do local do atendimento $n=2$; intercorrências pessoais $n=2$; indisponibilidade de presença no horário das sessões $\mathrm{n}=5$.

Sete (7) participantes foram excluídos do estudo por apresentarem as seguintes condições: acidente de moto $n=1$; lombalgia $n=3$; dor femoropatelar $n=2$. Também tivemos um participante que foi excluído, pois omitiu a informação referente à prática regular de atividades físicas. 


\section{Divulgações Intranet e Internet}

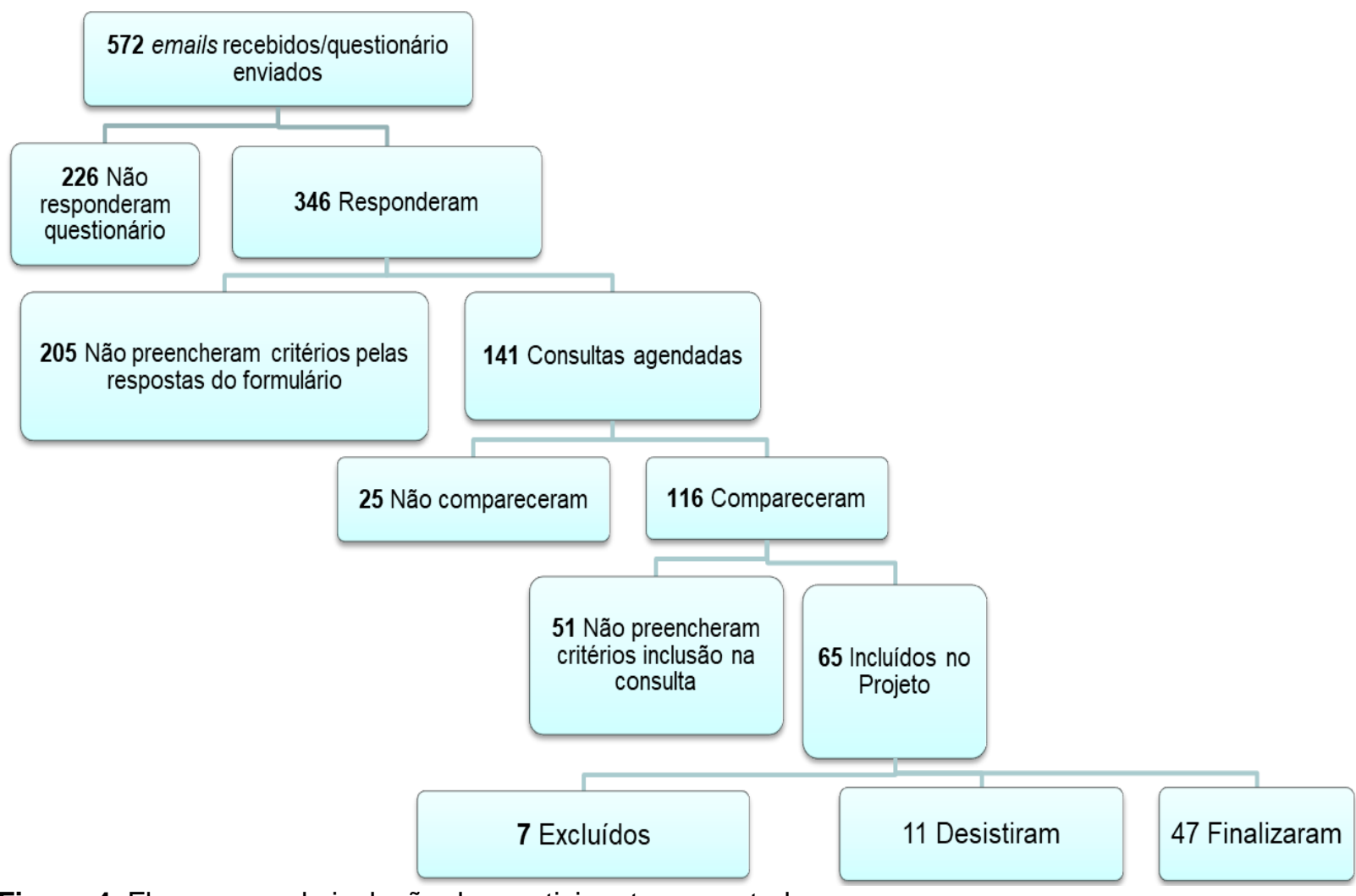

Figura 4. Fluxograma da inclusão dos participantes no estudo

Os aspectos demográficos e a caracterização dos participantes que compõem a amostra estão detalhados nas tabelas 1 e 2 , e os dados estão apresentados como média e desvio padrão (DP). A amostra é composta por 47 participantes, com predominância do sexo feminino; 30 (63,8\%) mulheres e 17 (36,2\%) homens. Com média de idade de 55,4 anos, média de peso corporal de 79,0kg e IMC médio de $29,3 \mathrm{~kg} / \mathrm{m}^{2}$.

Tabela 1. Características pessoais e dados antropométricos dos participantes

\begin{tabular}{lc}
\hline Características & Variação \\
\hline Sexo (\%) & $30(63,8)$ \\
Feminino & $17(36,2)$ \\
Masculino & \\
Idade (anos) & $55,4(5,1)$ \\
Média (DP) & $45 ; 65$ \\
$\quad$ Mínimo; Máximo & \\
Peso (kg) & \\
\hline
\end{tabular}




\begin{tabular}{lc}
...continuação & \\
\hline Média (DP) & $79,0(13,1)$ \\
Mínimo; Máximo & 49,$5 ; 111,2$ \\
Altura $(\mathrm{m})$ & \\
$\quad$ Média (DP) & $1,64(0,09)$ \\
Mínimo; Máximo & 1,$48 ; 1,92$ \\
Índice de massa corporal $\left(\mathrm{kg} / \mathrm{m}^{2}\right)$ & \\
$\quad$ Média (DP) & $29,3(3,5)$ \\
Mínimo; Máximo & 20,$5 ; 35,0$ \\
\hline
\end{tabular}

DP: desvio padrão. $\mathrm{N}=47$.

Observamos que o tempo de sintomas (Tabela 2) apresentou uma variação entre 0,6 e 20 anos, com metade dos participantes apresentando sintomas há no máximo três anos (primeiro quartil $=$ dois anos e terceiro quartil = quatro anos). No exame físico, $29(61,7 \%)$ eram neutros e $18(38,3 \%)$ apresentavam presença de desvio, seis $(12,8 \%)$ com tipo varo e $12(25,5 \%)$ valgos.

Em relação à lateralidade de queixa e sintomas, observou-se a prevalência da dominância do lado direito $(45 ; 95,7 \%)$ e quanto ao lado de maior queixa, $20(42,6 \%)$ apresentavam sintomas no lado direito e $27(57,4 \%)$ no lado esquerdo.

Os médicos ortopedistas avaliaram as radiografias dos joelhos do lado mais sintomático utilizando a classificação de Kellgren e Lawrence e classificaram $32(68,1 \%)$ pacientes em grau 2 (leve) e 15 (31,9\%) em grau 3 (moderado).

Tabela 2. Características da doença dos participantes

\begin{tabular}{lc}
\hline Características & Variação \\
\hline Tempo de sintomas (anos) & $3,0(2,0 ; 4,0)$ \\
$\quad$ Mediana (Q1; Q3) & 0,$6 ; 20,0$ \\
$\quad$ Mínimo; Máximo & \\
Desvio (\%) & $29(61,7)$ \\
$\quad$ Neutro & $6(12,8)$ \\
$\quad$ Varo & $12(25,5)$ \\
$\quad$ Valgo & \\
Lado dominante (\%) & $45(95,7)$ \\
$\quad$ Direito & $2(4,3)$ \\
$\quad$ Esquerdo & \\
Lado com queixa (\%) & $20(42,6)$ \\
$\quad$ Direito & $27(57,4)$ \\
$\quad$ Esquerdo & \\
Escala radiográfica conforme a classificação de Kellgren e & $32(68,1)$ \\
Lawrence no lado sintomático (\%) & $15(31,9)$ \\
2 &
\end{tabular}

Q1: primeiro quartil; Q3: terceiro quartil. $\mathrm{N}=47$. 
Optamos em recalcular o poder estatístico das análises utilizando a amostra de 47 participantes. O resultado mostrou que 47 participantes foram suficientes para detectar variação significante entre as avaliações pré e pós-tratamento no escore WOMAC padronizado, com poder observado >99\%.

Considerando o escore WOMAC padronizado (obtido dividindo-se o escore total por 96 pontos e multiplicando por 100) observamos na amostra de 47 participantes, média de $37,6 \%$ na avaliação pré e $16,2 \%$ na avaliação pós, representando uma redução de $-21,4 \%(p<0,001)$. Os dados obtidos com a escala WOMAC para avaliação da dor, rigidez e função física durante as atividades diárias mostrou redução significativa nos escores total e dos domínios ( $p<0,001$ em todas as comparações) na avaliação pós-comparado à avaliação pré-tratamento (Tabela 3).

Tabela 3. Dados do questionário WOMAC

\begin{tabular}{lccccc}
\hline \multirow{2}{*}{$\begin{array}{l}\text { Escores do } \\
\text { Questionário }\end{array}$} & \multicolumn{2}{c}{ Avaliação } & & \multicolumn{2}{c}{ Variação } \\
\cline { 2 - 3 } \cline { 5 - 6 } & Pré-reabilitação & Pós-reabilitação & & $\begin{array}{c}\text { Contraste } \\
\text { (Pós - Pré) }\end{array}$ & Valor-p \\
\hline Domínio dor & $8,1(7,1 ; 9,2)$ & $3,6(3,0 ; 4,3)$ & & $-4,5(-5,5 ;-3,5)$ & $<0,001$ \\
Domínio rigidez & $3,2(2,7 ; 3,8)$ & $1,3(0,9 ; 1,7)$ & & $-1,9(-2,5 ;-1,3)$ & $<0,001$ \\
Domínio mobilidade & $24,7(21,2 ; 28,2)$ & $10,7(8,0 ; 13,3)$ & & $-14,1(-17,1 ;-11,0)$ & $<0,001$ \\
Escore total & $36,1(31,5 ; 40,8)$ & $15,6(12,2 ; 19,0)$ & & $-20,6(-24,7 ;-16,4)$ & $<0,001$ \\
Escore total $\div 96^{*}$ & $0,38(0,33 ; 0,43)$ & $0,16(0,13 ; 0,20)$ & & $-0,21(-0,26 ;-0,17)$ & $<0,001$ \\
\hline
\end{tabular}

Valores expressos por médias estimadas (IC 95\%); * escore máximo possível. N=47.

Os participantes preencheram o questionário de qualidade de vida EQ-5D-3L no dia 0 (pré-reabilitação) e no final do protocolo de reabilitação, após 8 semanas (pós-reabilitação) e observou-se aumento significativo nos escores de estado de saúde $(p<0,001)$ e EQ-EVA $(p<0,001)$ na avaliação pós-comparado à avaliação inicial (Tabela 4).

Tabela 4. Dados do questionário de qualidade de vida EQ-5D-3L

\begin{tabular}{|c|c|c|c|c|}
\hline \multirow[b]{2}{*}{ Questionário } & \multicolumn{2}{|c|}{ Avaliação } & \multicolumn{2}{|l|}{ Variação } \\
\hline & Pré-reabilitação & Pós-reabilitação & $\begin{array}{l}\text { Contraste } \\
\text { (Pós - Pré) }\end{array}$ & Valor-p \\
\hline $\begin{array}{l}\text { Escore de } \\
\text { estado de } \\
\text { saúde }\end{array}$ & $0,623(0,574 ; 0,676)$ & $0,786(0,744 ; 0,829)$ & $0,163(0,100 ; 0,227)$ & $<0,001$ \\
\hline EVA & $68,4(64,0 ; 73,1)$ & $82,1(78,7 ; 85,7)$ & $13,7(10,2 ; 17,2)$ & $<0,001$ \\
\hline
\end{tabular}

A EVA foi utilizada como medida da intensidade da dor e foi aplicada nos participantes no dia 0 (pré-reabilitação) e no final do protocolo de reabilitação, após 
8 semanas. Observaram-se evidências de redução significativa $(p<0,001)$ na avaliação pós-comparada à avaliação pré-reabilitação (Tabela 5).

Tabela 5. Dados da Escala Visual Analógica de Dor

\begin{tabular}{lccccc}
\hline \multirow{2}{*}{ EVA } & \multicolumn{2}{c}{ Avaliação } & & \multicolumn{2}{c}{ Variação } \\
\cline { 2 - 3 } \cline { 5 - 6 } & Pré-reabilitação & Pós-reabilitação & & $\begin{array}{c}\text { Contraste } \\
\text { (Pós - Pré) }\end{array}$ & Valor-p \\
\hline Escore de dor & $2,82(2,51 ; 3,16)$ & $1,32(1,01 ; 1,73)$ & & $-1,50(-1,90 ;-1,10)$ & $<0,001$ \\
\hline Valores expressos por médias estimadas $($ IC $95 \%)$. EVA: Escala Visual Analógica. $\mathrm{N}=47$.
\end{tabular}

O TUG foi aplicado no dia 0 (pré-reabilitação) e final do protocolo de reabilitação para avaliar a habilidade de mobilidade dos participantes. Para análise das medidas (Tabela 6) os lados foram considerados em lado acometido pela osteoartrose (OA, lado com queixa) e lado $\mathrm{CL}$. Os resultados mostram que houve redução significativa no tempo para execução do teste ( $p<0,001$ em ambos os lados).

Tabela 6. Dados do Teste Timed Up and Go

\begin{tabular}{llllcl}
\hline \multirow{2}{*}{$\begin{array}{l}\text { TUG } \\
\text { (segundos) }\end{array}$} & \multicolumn{2}{c}{ Avaliação } & & \multicolumn{2}{c}{ Variação } \\
\cline { 2 - 3 } \cline { 5 - 6 } & Pré-reabilitação & Pós-reabilitação & & $\begin{array}{c}\text { Contraste } \\
\text { (Pós - Pré) }\end{array}$ & Valor-p \\
\hline Lado OA & $7,76(7,43 ; 8,12)$ & $7,36(7,07 ; 7,67)$ & & $-0,40(-0,57 ;-0,23)$ & $<0,001$ \\
Lado CL & $7,63(7,35 ; 7,93)$ & $7,29(7,03 ; 7,56)$ & & $-0,35(-0,49 ;-0,20)$ & $<0,001$ \\
\hline
\end{tabular}

Analisamos o pico de torque isométrico normalizado (PTIn), Índice Contrátil Isométrico normalizado (ICn), o Pico de torque concêntrico isocinético normalizado (PTCn) e o Wn; todos os dados foram normalizados pelo peso corporal do participante, obtidos antes da sessão de cada avaliação no dinamômetro isocinético para reduzir a variabilidade dos dados devido a diferenças antropométricas entre homens e mulheres.

Observou-se aumento significativo nas medidas de PTIn e ICn isométricas em extensão e em flexão em ambos os lados $(p<0,05$ em todas as comparações), demonstrando que o protocolo de exercício proposto contribuiu para o aumento da capacidade de gerar força máxima (PTIn em extensão e PTIn em flexão) e também na capacidade de sustentação de força (ICn em extensão e ICn em flexão) (Tabela 7). 
Tabela 7. Dados da avaliação de força isométrica

\begin{tabular}{|c|c|c|c|c|}
\hline \multirow[b]{2}{*}{ Força isométrica } & \multicolumn{2}{|c|}{ Avaliação } & \multicolumn{2}{|c|}{ Variação } \\
\hline & Pré-reabilitação & Pós-reabilitação & $\begin{array}{l}\text { Contraste } \\
\text { (Pós - Pré) }\end{array}$ & Valor-p \\
\hline \multicolumn{5}{|l|}{ PTIn extensão (Nm/kg) } \\
\hline Lado OA & $1,67(1,45 ; 1,89)$ & $1,98(1,78 ; 2,19)$ & $0,31(0,20 ; 0,43)$ & $<0,001$ \\
\hline Lado CL & $1,84(1,61 ; 2,07)$ & $2,16(1,93 ; 2,38)$ & $0,32(0,15 ; 0,48)$ & $<0,001$ \\
\hline Contraste (OA - CL) & $-0,17(-0,33 ;-0,01)$ & $-0,17(-0,30 ;-0,05)$ & & \\
\hline Valor-p & 0,033 & 0,007 & & \\
\hline \multicolumn{5}{|l|}{ PTIn flexão (Nm/kg) } \\
\hline Lado OA & $0,84(0,73 ; 0,94)$ & $1,02(0,91 ; 1,12)$ & $0,18(0,12 ; 0,23)$ & $<0,001$ \\
\hline Lado CL & $0,89(0,78 ; 0,99)$ & $1,04(0,94 ; 1,14)$ & $0,15(0,10 ; 0,21)$ & $<0,001$ \\
\hline Contraste (OA - CL) & $-0,05(-0,11 ; 0,01)$ & $-0,02(-0,07 ; 0,02)$ & & \\
\hline Valor-p & 0,116 & 0,323 & & \\
\hline \multicolumn{5}{|l|}{ ICln extensão (Nm/kg) } \\
\hline Lado OA & $5,62(4,77 ; 6,47)$ & $6,77(5,98 ; 7,56)$ & $1,15(0,51 ; 1,79)$ & 0,001 \\
\hline Lado CL & $6,24(5,48 ; 6,99)$ & $7,51(6,75 ; 8,27)$ & $1,27(0,83 ; 1,72)$ & $<0,001$ \\
\hline Contraste (OA - CL) & $-0,62(-1,21 ;-0,03)$ & $-0,74(-1,25 ;-0,23)$ & & \\
\hline Valor-p & 0,039 & 0,005 & & \\
\hline \multicolumn{5}{|l|}{ ICIn flexão (Nm/kg) } \\
\hline Lado OA & $2,75(2,36 ; 3,13)$ & $3,47(3,11 ; 3,84)$ & $0,73(0,50 ; 0,95)$ & $<0,001$ \\
\hline Lado CL & $2,95(2,56 ; 3,35)$ & $3,57(3,21 ; 3,94)$ & $0,62(0,38 ; 0,86)$ & $<0,001$ \\
\hline Contraste $(\mathrm{OA}-\mathrm{CL})$ & $-0,21(-0,48 ; 0,06)$ & $-0,10(-0,29 ; 0,09)$ & & \\
\hline Valor-p & 0,126 & 0,299 & & \\
\hline
\end{tabular}

A produção de torque dos músculos extensores do joelho avaliada durante a contração isocinética a $600 . \mathrm{s}-1$ aumentou para o lado $\mathrm{CL}$, porém o mesmo não ocorreu para o lado acometido pela osteoartrose. Observou-se aumento significativo nas medidas de PTCn dos músculos flexores do joelho em ambos os lados $(p<0,05)$ (Tabela 8).

Tabela 8. Dados do teste de força isocinética

\begin{tabular}{|c|c|c|c|c|}
\hline \multirow[b]{2}{*}{ Força isocinética } & \multicolumn{2}{|c|}{ Avaliação } & \multicolumn{2}{|l|}{ Variação } \\
\hline & Pré-reabilitação & Pós-reabilitação & $\begin{array}{l}\text { Contraste } \\
\text { (Pós - Pré) }\end{array}$ & Valor-p \\
\hline \multicolumn{5}{|l|}{ PTCn extensão (Nm/kg) } \\
\hline Lado OA & $1,34(1,17 ; 1,52)$ & $1,45(1,27 ; 1,62)$ & $0,10(-0,02 ; 0,22)$ & 0,095 \\
\hline Lado CL & $1,46(1,29 ; 1,63)$ & $1,61(1,44 ; 1,77)$ & $0,15(0,05 ; 0,25)$ & 0,004 \\
\hline Contraste (OA - CL) & $-0,12(-0,24 ; 0,01)$ & $-0,16(-0,26 ;-0,06)$ & & \\
\hline Valor-p & 0,057 & 0,002 & & \\
\hline \multicolumn{5}{|l|}{ PTCn flexão (Nm/kg) } \\
\hline Lado OA & $0,63(0,53 ; 0,73)$ & $0,79(0,70 ; 0,89)$ & $0,16(0,10 ; 0,22)$ & $<0,001$ \\
\hline Lado CL & $0,71(0,62 ; 0,81)$ & $0,82(0,72 ; 0,91)$ & $0,11(0,05 ; 0,16)$ & $<0,001$ \\
\hline Contraste (OA - CL) & $-0,08(-0,14 ;-0,02)$ & $-0,02(-0,08 ; 0,03)$ & & \\
\hline
\end{tabular}




\begin{tabular}{|c|c|c|c|c|}
\hline Valor-p & 0,007 & 0,360 & & \\
\hline \multicolumn{5}{|l|}{ Razão PTC HQ (\%) } \\
\hline Lado OA & $47,52(42,41 ; 53,24)$ & $56,12(50,70 ; 62,12)$ & $8,61(1,98 ; 15,24)$ & 0,011 \\
\hline Lado CL & $48,05(45,06 ; 51,23)$ & $51,19(46,90 ; 55,87)$ & $3,14(-0,50 ; 6,78)$ & 0,090 \\
\hline Contraste $(\mathrm{OA}-\mathrm{CL})$ & $-0,53(-5,38 ; 4,32)$ & $4,93(-0,86 ; 10,72)$ & & \\
\hline Valor-p & 0,828 & 0,094 & & \\
\hline
\end{tabular}

A tabela 9 demonstra os resultados obtidos após a análise do Wkn pré e pós-tratamento, comparando o lado acometido (AO) com o lado CL. Observou-se evidências de aumento significativo nas medidas de Wkn isocinéticas em extensão no lado $C L$ e em flexão em ambos os lados ( $p<0,05$ em todas as comparações).

Tabela 9. Dados da avaliação do trabalho isocinético

\begin{tabular}{|c|c|c|c|c|}
\hline \multirow[b]{2}{*}{ Trabalho Isocinético } & \multicolumn{2}{|c|}{ Avaliação } & \multicolumn{2}{|c|}{ Variação } \\
\hline & Pré-reabilitação & Pós-reabilitação & $\begin{array}{l}\text { Contraste } \\
\text { (Pós - Pré) }\end{array}$ & Valor-p \\
\hline \multicolumn{5}{|l|}{ Extensão $(\mathrm{J} / \mathrm{kg})$} \\
\hline Lado OA & $1,11(0,97 ; 1,26)$ & $1,19(1,05 ; 1,33)$ & $0,08(-0,03 ; 0,18)$ & 0,153 \\
\hline Lado CL & $1,22(1,08 ; 1,36)$ & $1,33(1,20 ; 1,46)$ & $0,11(0,03 ; 0,20)$ & 0,007 \\
\hline Contraste $(O A-C L)$ & $-0,10(-0,21 ; 0,00)$ & $-0,14(-0,22 ;-0,06)$ & & \\
\hline Valor-p & 0,053 & 0,001 & & \\
\hline \multicolumn{5}{|l|}{ Flexão (J/kg) } \\
\hline Lado OA & $0,55(0,46 ; 0,64)$ & $0,69(0,60 ; 0,77)$ & $0,14(0,08 ; 0,19)$ & $<0,001$ \\
\hline Lado CL & $0,61(0,52 ; 0,70)$ & $0,70(0,62 ; 0,79)$ & $0,10(0,05 ; 0,14)$ & $<0,001$ \\
\hline Contraste $(O A-C L)$ & $-0,06(-0,11 ;-0,01)$ & $-0,02(-0,07 ; 0,03)$ & & \\
\hline Valor-p & 0,031 & 0,458 & & \\
\hline
\end{tabular}

O teste incremental foi realizado em três momentos durante o protocolo de reabilitação, no dia 0 (pré-reabilitação), momento intermediário e no final do protocolo de reabilitação, mensurando o estágio atingido, a frequência cardíaca e o escore da escala de Borg. Comparando os estágios alcançados pelos participantes (Tabela 10), apesar da tendência de aumento nos momentos intermediário e pósreabilitação, não observamos evidências de variação significativa entre as avaliações pré e intermediária $(p=0,446)$, pré e pós $(p=0,297)$ e intermediária e pós $(p>0,999)$. 
Tabela 10. Dados do teste incremental

\begin{tabular}{lccc}
\hline \multirow{2}{*}{$\begin{array}{l}\text { Estágio } \\
\text { (\%) }\end{array}$} & \multicolumn{3}{c}{ Avaliação } \\
\cline { 2 - 4 } & Pré-reabilitação & Intermediária & Pós-reabilitação \\
\hline 1 & $4(8,5)$ & $2(4,3)$ & $2(4,3)$ \\
2 & $23(48,9)$ & $17(36,2)$ & $16(34,0)$ \\
3 & $16(34,0)$ & $24(51,1)$ & $23(48,9)$ \\
4 & $4(8,5)$ & $4(8,5)$ & $6(12,8)$ \\
Contrastes & & & \\
Préx x Intermediária & $\mathrm{p}=0,446$ & & \\
Pré x Pós & $\mathrm{p}=0,297$ & & \\
Intermediária x Pós & $\mathrm{p}>0,999$ & & \\
\hline $\mathrm{N}=47$. & &
\end{tabular}

Observamos redução do escore de esforço na escala de Borg (Tabela 11) na comparação do momento pré com o intermediário $(p<0,001)$ e com 0 pós ( $p=0,005)$; não observamos variação significativa da frequência cardíaca entre as avaliações pré e intermediária $(p>0,999)$, pré e pós $(p>0,999)$ e intermediária e pós $(p>0,999)$.

Tabela 11. Dados da Escala de Borg durante o teste incremental

\begin{tabular}{lccc}
\hline \multirow{2}{*}{ Escores } & \multicolumn{3}{c}{ Avaliação } \\
\cline { 2 - 4 } & Pré-reabilitação & Intermediária & Pós-reabilitação \\
\hline Escore da Escala de Borg & $14,6(14,0 ; 15,2)$ & $13,7(13,0 ; 14,3)$ & $13,8(13,2 ; 14,5)$ \\
$\quad$ Contrastes & & & \\
Intermediário - Pré & $-0,9(-1,5 ;-0,4)$ & $\mathrm{p}<0,001$ & \\
Pós - Pré & $-0,8(-1,3 ;-0,2)$ & $\mathrm{p}=0,005$ & \\
Pós - Intermediário & $0,2(-0,3 ; 0,6)$ & $\mathrm{p}=0,465$ & \\
Frequência cardíaca (bpm) & $117,1(112,9 ; 121,4)$ & $116,3(112,5 ; 120,1)$ & $117,1(112,7 ; 121,5)$ \\
Contrastes & & & \\
Intermediário - Pré & $-0,9(-4,0 ; 2,3)$ & $>0,999$ & \\
Pós - Pré & $0,0(-3,4 ; 3,3)$ & $>0,999$ & \\
Pós - Intermediário & $0,8(-2,3 ; 3,9)$ & $>0,999$ & \\
\hline
\end{tabular}

Valores expressos por médias estimadas (IC 95\%). N=47.

O teste de 1RM foi realizado nos tempos pré, intermediário para controle da carga do treinamento, e pós-protocolo de reabilitação e observamos evidências de aumento significativo nas cargas dos exercícios leg press, cadeira flexora e cadeira extensora (Tabela 12) realizados pelos participantes na avaliação intermediária comparado à avaliação pré e na avaliação pós comparada à intermediária ( $p<0,001$ em todas as comparações). 
Tabela 12. Dados do teste de uma repetição máxima

\begin{tabular}{lccc}
\hline Teste de Uma & \multicolumn{3}{c}{ Avaliação } \\
\cline { 2 - 4 } Repetição Máxima & Pré-reabilitação & Intermediária & Pós-reabilitação \\
\hline Leg Press (kg) & $97,4(85,4 ; 109,3)$ & $123,8(112,2 ; 135,4)$ & $143,0(131,2 ; 154,9)$ \\
Contrastes & & & \\
Intermediário - Pré & $26,4(20,4 ; 32,4)$ & $<0,001$ & \\
Pós - Pré & $45,7(39,5 ; 51,9)$ & $<0,001$ & \\
Pós - Intermediário & $19,3(14,8 ; 23,8)$ & $<0,001$ & \\
Cadeira flexora (kg) & $34,7(31,0 ; 38,8)$ & $44,2(39,7 ; 49,2)$ & \\
Contrastes & & & \\
Intermediário - Pré & $9,5(7,4 ; 11,6)$ & $<0,001$ & \\
Pós - Pré & $17,1(13,5 ; 20,7)$ & $<0,001$ & \\
Pós - Intermediário & $7,6(5,2 ; 10,0)$ & $<0,001$ & \\
Cadeira extensora (kg) & $38,2(33,5 ; 43,6)$ & $47,0(41,5 ; 53,1)$ & \\
Contrastes & & & \\
Intermediário - Pré & $8,8(6,3 ; 11,2)$ & $<0,001$ & \\
Pós - Pré & $16,0(12,1 ; 19,9)$ & $<0,001$ & \\
Pós - Intermediário & $7,2(5,3 ; 9,1)$ & $<0,001$ & \\
\hline Valores expressos por médias estimadas (IC $95 \%) . N=47$. &
\end{tabular}

A tabela 13 demonstra os resultados obtidos com modelos de regressão logística binária ajustados. ${ }^{(48)}$ Não observamos evidências de associação entre variação maior ou igual a $8,8 \%$ no escore WOMAC, ${ }^{(49)}$ padronizado como indicador de melhora clínica e o escore EQ-5D-3L - EVA, sexo, idade, IMC e grau de artrose. Este resultado demonstra que a melhora clínica dos participantes não está relacionada a fatores intrínsecos dos mesmos.

Tabela 13. Associação entre variação no WOMAC padronizado e características dos participantes

\begin{tabular}{|c|c|c|c|c|}
\hline & \multicolumn{2}{|c|}{$\begin{array}{c}\text { Variação no escore WOMAC } \\
\text { padronizado }\end{array}$} & \multirow{2}{*}{$\begin{array}{c}\text { RC } \\
(\text { IC 95\%) }\end{array}$} & \multirow{2}{*}{ Valor-p ${ }^{\#}$} \\
\hline & $\begin{array}{l}<8,8 \% \\
(n=10)\end{array}$ & $\begin{array}{l}\geq 8,8 \% \\
(n=37)\end{array}$ & & \\
\hline \multicolumn{5}{|l|}{ Idade } \\
\hline Mediana (Q1; Q3) & $55,5(46,0 ; 61,0)$ & $57,0(53,0 ; 59,0)$ & $1,059(0,922 ; 1,215)$ & 0,418 \\
\hline \multicolumn{5}{|l|}{ Sexo } \\
\hline Masculino & $6(35,3 \%)$ & $11(64,7 \%)$ & 1,00 & \\
\hline Feminino & $4(13,3 \%)$ & $26(86,7 \%)$ & $3,545(0,833 ; 15,089)$ & 0,087 \\
\hline \multicolumn{5}{|l|}{ Classificação do IMC } \\
\hline$\leq 24,99 \mathrm{~kg} / \mathrm{m}^{2}$ & $1(25,0 \%)$ & $3(75,0 \%)$ & $1,200(0,103 ; 13,951)$ & 0,884 \\
\hline 25 a $29,99 \mathrm{~kg} / \mathrm{m}^{2}$ & $3(13,6 \%)$ & $19(86,4 \%)$ & $2,533(0,542 ; 11,845)$ & 0,238 \\
\hline$\geq 30 \mathrm{~kg} / \mathrm{m}^{2}$ & $6(28,6 \%)$ & $15(71,4 \%)$ & 1,00 & \\
\hline \multicolumn{5}{|l|}{$\begin{array}{l}\text { Classificação de } \\
\text { Kelgren e Lawrence }\end{array}$} \\
\hline 2 & $8(25,0 \%)$ & $24(75,0 \%)$ & 1,00 & \\
\hline
\end{tabular}


...continuação

\begin{tabular}{ccccc}
\hline 3 & $2(13,3 \%)$ & $13(86,7 \%)$ & $2,167(0,400 ; 11,743)$ & 0,370 \\
EuroQol basal & & & & \\
Mediana (Q1; Q3) & $0,727(0,620 ; 0,779)$ & $0,620(0,516 ; 0,691)$ & $0,006(0,000 ; 1,801)$ & 0,078 \\
EVA para dor basal & $3,5(2,0 ; 4,0)$ & $3,0(2,0 ; 4,0)$ & $0,771(0,408 ; 1,455)$ & 0,422 \\
\hline
\end{tabular}

WOMAC: Western Ontario e McMaster Universities (WOMAC); RC: razão de chances (Intervalo de Confiança de $95 \%{ }^{\#}$ ) e valores-p $p^{\#}$ obtidos pelo ajuste de modelos de regressão logística binária. IMC: Índice de Massa Corporal. EVA: Escala Visual Analógica. N=47. 


\section{DISCUSSÃO}

A terapia por exercício é uma intervenção eficaz para redução da dor nas articulações e melhora da função física em pacientes com osteoartrose de joelho, sendo recomendada como a principal intervenção não medicamentosa pelas diretrizes internacionais de gerenciamento de osteoartrose. ${ }^{(50)}$

O presente estudo analisou os resultados clínicos em indivíduos com osteoartrose leve e moderada de joelho após tratamento conservador baseado em programa de exercícios simplificado para três grupos musculares. Ao final do estudo, 47 participantes de ambos os sexos, sendo $63,8 \%$ do sexo feminino foram avaliados, corroborando com a literatura que sugere que mulheres têm 2,6 vezes mais chances de desenvolver osteoartrose em relação aos homens. ${ }^{(51)}$ Os médicos ortopedistas avaliaram as radiografias dos joelhos dos participantes utilizando a classificação radiográfica Kellgren e Lawrence, sendo que $68,1 \%$ dos participantes foram classificados com grau 2 e, 31,9\% dos participantes foram classificados com grau 3 , ou seja, os participantes apresentavam osteoartrose de intensidade leve a moderada. A média de idade dos participantes foi 55,4 anos, e o IMC em média foi de 29,3; metade dos participantes apresentavam sintomas há no máximo três anos. Os dados demográficos dos participantes do nosso estudo são semelhantes à população analisada em outros estudos sobre análise de protocolo de reabilitação, com média de 30 de IMC e maioria do sexo feminino (65\%) com média de idade de 64 anos. ${ }^{(49,52)}$

O exame físico em relação ao alinhamento dos joelhos mostrou que $61,7 \%$ eram neutros e $38,3 \%$ apresentavam presença de desvio, sendo $12,8 \%$ em varo e $25,5 \%$ em valgo, divergindo da literatura que relata que a osteoartrose do compartimento medial é a mais comum e está associada ao alinhamento em varo. ${ }^{(53)}$ Embora os participantes do nosso estudo tenham reportado o lado direito como dominante $(95,7 \%)$, o lado da queixa de dor e prevalência da osteoartrose na maioria dos participantes foi reportado como lado esquerdo $(57,4 \%)$. Diferentemente, estudo comparando o efeito de exercícios domiciliares em pacientes com osteoartrose, graus 2 e 3 e média de idade de 57 anos, reportou predominância de osteoartrose no lado direito. ${ }^{(53)}$ Outros fatores não investigados podem estar relacionados a predominância do lado acometido, como atividade laboral, prática de atividade física entre outros. 
Estudo randomizado controlado onde os participantes do grupo de intervenção realizaram programa de exercícios individualizados por 20 semanas, com 2 sessões de 30-60 minutos por semana, relatou melhora significativa na escala WOMAC. ${ }^{(50)}$ O protocolo proposto no presente estudo utilizou apenas exercícios para três grupos musculares (isquiotibiais, quadríceps e glúteos) 3 vezes por semana durante oito semanas e os resultados obtidos mostram que o fortalecimento destes músculos tem forte relação com a melhora na escala WOMAC, semelhante ao estudo citado. Recente estudo enfatiza que os protocolos de reabilitação de joelho devam ter uma duração relativamente curta, menor ou igual a 12 semanas para garantir sua efetividade. ${ }^{(54)}$ Os dados obtidos com presente estudo corroboram com estes dados, mostrando que a prática de exercícios por 8 semanas, com frequência 3x/semana, é suficiente para obter resultados clínicos positivos na escala WOMAC.

A dor é descrita como estado alterado da saúde de uma pessoa e pode ser influenciada por fatores biopsicossociais, dos quais muitos podem ser modificados. O paciente deve ser orientado para o melhor manejo da dor, assumindo assim o comando de seu tratamento através da adoção de uma mentalidade positiva que reforce a importância da autogestão de sua doença a longo prazo. ${ }^{(55)}$

Os resultados em relação à dor avaliada com a ferramenta WOMAC e EVA mostram que a intervenção proposta no presente estudo melhora a percepção da dor pelos participantes após a reabilitação. Este conjunto de resultados corrobora com revisão sistemática de 94 estudos clínicos avaliando 112 grupos de intervenção em pacientes com osteoartrose de joelho, concluindo que o aumento da força muscular resulta na redução da dor em indivíduos com osteoartrose. ${ }^{(56)}$

Revisão sistemática e meta-análise de ensaios clínicos randomizados com grupos de exercícios somente com fortalecimento muscular sem carga, ou seja, exercício concêntrico-excêntrico, isométrico ou isocinético em condições que não sustentam o peso, concluiu que exercícios de fortalecimento muscular com ou sem descarga de peso e exercícios aeróbicos são eficazes para o alívio da dor, nas primeiras oito semanas de intervenção. A revisão abordou estudos sobre o efeito de fortalecimento muscular de sustentação de peso (ou seja, exercícios em máquina leg press) e exercício aeróbico (caminhada, Tai Chi). ${ }^{(57)}$

Outra revisão sistemática sobre o uso de exercícios em pacientes com osteoartrose de joelho, concluiu que nos estudos que utilizaram apenas o 
exercício como tratamento o efeito na redução da dor foi pequeno quando comparado a combinação de exercícios e terapia manual. ${ }^{(58)}$

O exercício isométrico de quadríceps também é abordado como tratamento eficaz para pacientes com osteoartrose de joelho, sendo reportada uma redução significativa da dor após 5 a 8 semanas de intervenção. ${ }^{(59,60)}$ Embora 0 protocolo simplificado de fisioterapia apresentado no presente estudo não envolva exercícios isométricos, apenas exercícios de fortalecimento de três grupos musculares e alongamentos musculares ativos, também observamos redução significativa da dor após oito semanas de tratamento, sugerindo que o exercício isotônico de quadríceps é efetivo para melhora da dor.

A osteoartrose está associada a deteriorações substanciais na qualidade de vida relacionada à saúde. ${ }^{(61)}$ Um estudo recente no Reino Unido classificou a osteoartrose como a terceira maior causa de perda de qualidade de vida relacionada a onze condições crônicas de saúde. ${ }^{(62)}$

Ao final do protocolo simplificado de reabilitação com fortalecimento de três grupos musculares, observamos aumento significativo nos escores de estado de saúde e EQ-EVA avaliados através do questionário EQ-5D-3L na avaliação póscomparada à avaliação inicial. Demonstramos que um protocolo de exercícios simples, com menor duração de tempo das sessões e realizado em apenas 8 semanas, apresentam resultados semelhantes aos dados de outro estudo, com 67 participantes com osteoartrose classificada em leve a grave e média de idade de 69 anos, os quais foram submetidos a um programa de exercícios de 90 minutos, duas vezes por semana durante 12 semanas. ${ }^{(63)}$ Outro estudo mostrou que pessoas com osteoartrose e dor no joelho apresentam escores mais baixos no questionário EQ-5D-3L, tendo um impacto negativo na qualidade de vida. ${ }^{(64)} \mathrm{Em}$ contraste, nossos participantes reportaram escores medianos na escala EQ-5D-3L antes da reabilitação, o que pode ter contribuído para o aumento significativo na qualidade de vida dos mesmos.

A osteoartrose é a doença articular crônica mais comum em indivíduos de meia idade e está frequentemente associada a deficiências funcionais de curto e longo prazo. ${ }^{(65)}$ Os pacientes classificam a melhora na função física como um dos resultados mais importantes do tratamento, além da redução da dor. ${ }^{(66)} \mathrm{O}$ déficit de mobilidade, definido como a necessidade de ajuda para caminhar ou subir escadas, relacionado a osteoartrose de joelho é maior do que o atribuído a qualquer outra condição clínica em pessoas com idade superior a 65 anos. ${ }^{(67)}$ Após a finalização do 
protocolo de exercícios observamos redução significativa nos escores total e dos domínios na avaliação pós comparada à avaliação pré-tratamento com a escala WOMAC para avaliação da dor, rigidez e função física durante as atividades diárias. Estudo com protocolo de exercícios combinados de fortalecimento muscular e equilíbrio e agilidade, com 183 sujeitos com osteoartrose do joelho moderada a grave, sendo $67 \%$ mulheres com média de idade de 63,9 anos e IMC médio de 30,5 observou uma mudança de $8,8 \%$ na escala WOMAC após dois meses de tratamento. ${ }^{(49)}$ Embora 0 protocolo do presente estudo tenha utilizado apenas exercícios para três grupos musculares, obtivemos resultados semelhantes em relação a redução da escala WOMAC no mesmo período de tempo.

Revisão sistemática com dezoito estudos, totalizando 2.832 sujeitos, faixa etária média da coorte de 55 a 74 anos, mostrou melhora de 100\% nas medidas autorreferidas de dor, função física e desempenho após exercícios de resistência muscular com carga moderada e progressiva, num período de 1 a 6 meses, com frequência média de 3 vezes por semana e duração de 10 a 60 minutos. A revisão também relatou os principais motivos das desistências dos participantes, sendo: aumento da dor no joelho, aumento da dor em geral/outras áreas, restrições de tempo ou de viagem ou motivos pessoais. ${ }^{(68)}$ Nossos resultados confirmam os dados apresentados nesta revisão, pois ao final do protocolo simplificado de exercícios de fortalecimento de três grupos musculares, também observamos melhora na função física e dor nos participantes do estudo, além dos motivos de desistências de nossos participantes serem semelhantes (dificuldade em manter a frequência às sessões de fisioterapia exigida no estudo por morte na família; acidente de moto; residir distante do local do atendimento; lombalgia; intercorrências pessoais; dor femoropatelar; indisponibilidade de presença no horário das sessões e omissão de informação para critério de inclusão, isto é, praticava de atividades físicas regularmente).

O teste TUG avalia o desempenho da função física e foi validado como ferramenta adequada para portadores de osteoartrose de joelho de grau leve a moderado. ${ }^{(69)}$ No presente estudo observamos redução significativa no tempo para execução do teste após término do protocolo simplificado de exercícios para três grupos musculares. Diferentemente, estudo anterior avaliando um programa educacional de dois dias com orientações de autocuidados e exercícios para casa para portadores de osteoartrose de joelho leve a moderada não observou mudanças no TUG após 1 ano de acompanhamento. ${ }^{(70)}$ Enquanto, outro estudo avaliando exercícios 
resistidos de quadríceps realizados 2 vezes por semana durante oito semanas com participantes na maioria do sexo feminino com osteoartrose de joelho de graus leve a moderado, predominante do lado esquerdo, mostrou melhora significativa no teste TUG ao final do protocolo de tratamento. ${ }^{(71)}$ Diante da discordância de resultados apresentados nos diferentes estudos, é importante destacar que a utilização de apenas um teste para avaliação de função física em pacientes com osteoartrose não é adequado. No presente estudo optamos em considerar o Teste TUG, o WOMAC, o Teste Incremental, o Teste de 1RM e a Dinamometria Isocinética para avaliar a força muscular e função física dos participantes após a realização do protocolo simplificado de exercícios para osteoartrose de joelhos.

O Teste Incremental, também conhecido como teste de percepção de esforço, tem sido sugerido para mensurar o estágio atingido, a frequência cardíaca, em conjunto com a escala de Borg. ${ }^{(45)}$ Nossos resultados mostram que não há evidências de variação significativa na comparação entre as avaliações no momento pré e pós-protocolo de reabilitação. O teste foi usado como estimativa simples da resistência cardiorrespiratória para programação da intensidade do exercício de aquecimento prévio à aplicação do protocolo simplificado de fortalecimento de três grupos musculares de membros inferiores.

A avaliação da força muscular obtida pela dinamometria isocinética possibilita uma rápida análise quantitativa de parâmetros da função muscular incluindo o pico de torque e consiste no movimento forçado de um membro em velocidade angular constante. O equipamento utilizado para esta finalidade funciona sob 0 princípio da ação e reação e permite a utilização da capacidade muscular em toda a amplitude do movimento. ${ }^{(72)}$

Observamos que após o protocolo de exercícios de fortalecimento de três grupos musculares de membros inferiores há um aumento nas medidas do pico de torque e impulso contrátil isométricos em extensão e em flexão em ambos os lados. Em relação ao aumento do pico de torque isocinético, houve aumento para os flexores de ambos os lados, porém o pico de torque dos extensores aumentou para o membro inferior contralateral, mas o mesmo não ocorreu para o membro inferior acometido pela osteoartrose; resultado semelhante se deu para a mensuração do trabalho. Estudo com 100 pacientes com osteoartrose no compartimento medial do joelho, graus 3 e 4, com média de idade de 62,4 anos e IMC 29, submetidos a um programa de exercícios de fortalecimento muscular do quadríceps por 12 semanas (4 vezes por semanas), 
observou melhora significativa da força muscular dos extensores do joelho, ${ }^{(73)}$ contrariando os resultados obtidos ao final do protocolo simplificado de fortalecimento muscular, sugerindo que o resultado atingido por este estudo possivelmente está relacionado com o tempo de execução do protocolo de exercícios, por apenas 8 semanas, sugerido como período de treinamento em que ocorrem preferencialmente adaptações neurais em outro estudo. ${ }^{(74)}$

A análise dos desequilíbrios das forças musculares envolvidas no movimento de uma única articulação é importante para a prevenção de lesão. $\mathrm{Na}$ articulação do joelho, uma das estratégias para obter esse resultado é o cálculo da razão convencional, que é realizado com a divisão do PTCFn (isquiotibiais) pelo PTCEn (quadríceps) de um mesmo membro. ${ }^{(64,65)} \mathrm{O}$ valor de $60 \%$ resultante desta equação tem sido sugerido como valor ideal para o equilíbrio articular em avaliação isocinética na velocidade de $60^{\circ} . \mathrm{s}-1$, classificando os sujeitos que apresentam esse valor com risco diminuído de lesão na articulação do joelho. ${ }^{(44,75,76)}$

A razão do pico de torque isquiotibiais/quadríceps (PT H/Q) mostra que os participantes do nosso estudo não atingiram o índice de $60 \%$ na relação isquiotibiais quadríceps, embora observemos melhora da força muscular do membro inferior após o protocolo simplificado de exercícios. Revisão da literatura sobre a efetividade da prática de exercícios sugere que o exercício em geral influencia vários outros componentes além da força muscular no indivíduo, como função neuromuscular, condicionamento físico geral e saúde e fatores psicossociais que são possíveis mecanismos que podem influenciar mudanças nos resultados clínicos. ${ }^{(77)}$ Embora estes fatores não tenham sido avaliados no presente estudo, sugerimos que possivelmente os mesmos possam ter influenciado na melhora clínica dos participantes do nosso estudo.

Meta-análise avaliou aproximadamente 4.000 pacientes e concluiu que os protocolos de exercícios baseados em um único tipo de exercício, com objetivo de melhora da capacidade aeróbica, força muscular do quadríceps e/ou desempenho das extremidades inferiores, são mais eficazes na redução da dor e incapacidade relatada pelo paciente. Também demonstraram que a melhora relatada não tem relação com idade, sexo, IMC, classificação radiográfica ou dor basal. ${ }^{(78)}$ Nossos resultados corroboram com estes dados, pois observamos que a melhora clínica dos participantes não está relacionada a fatores intrínsecos dos mesmos, pois não observamos evidências de associação entre variação maior ou igual a 8,8\% no escore 
WOMAC (padronizado como indicador de melhora clínica) e os escores EQ-5D-3L, EVA, sexo, idade, IMC e grau de artrose. Desta forma, nossos dados sugerem que o protocolo proposto pode ser utilizado por uma grande variabilidade de indivíduos com osteoartrose, de forma independente das características como idade, sexo, grau da doença, índice de peso corporal e/ou dor. Acreditamos que os resultados deste estudo sejam relevantes para o tratamento de pacientes com osteoartrose de joelho que se submetem a um protocolo simplificado de exercícios de fortalecimento para três grupos musculares. 
6 CONCLUSÃO

1. O tratamento conservador simplificado para fortalecimento de três grupos musculares para pacientes portadores de osteoartrose de joelho foi efetivo na melhora da dor, funcionalidade, força muscular e qualidade de vida. 
7 ANEXOS

Anexo 1. Termo de Consentimento Livre e Esclarecido

\section{TERMO DE CONSENTIMENTO LIVRE E ESCLARECIDO}

O Sr.(a) está sendo convidado a participar de um estudo intitulado "Modulação de biomarcadores para osteoartrose após um programa de reabilitação." As informações abaixo estão sendo fornecidas para esclarecê-lo sobre sua possível participação voluntária neste estudo, que tem como objetivo descobrir novas substâncias no sangue para monitorar a osteartrose, avaliando a eficácia de um programa de reabilitação fisioterapêutica como tratamento. Este estudo será realizado da seguinte maneira: “Após consulta com médico ortopedista, que fará uma avaliação sobre o estado de saúde dos seus membros inferiores (coxa e perna), o Sr.(a) será encaminhado para as sessões de reabilitação com fisioterapeuta. A duração total da pesquisa será de 9 (nove) semanas, com 3 (três) sessões/dias por semana. Na primeira sessão, o Sr.(a) será direcionado(a) para alguns exames de sangue, razão pela qual o Sr.(a) estará em jejum de 6 horas. Depois da coleta o Sr.(a) será convidado(a) a preencher alguns questionários sobre dados pessoais, saúde mental, dor e dificuldades para realizar atividades diárias. Após, o Sr.(a) fará um teste de caminhada, acompanhado por um fisioterapeuta. Este teste analisara a posição do seu quadril, joelho e tornozelo enquanto caminha por uma distância de 4 (quatro) metros. Para isto, marcadores (pequenas bolinhas prateadas) serão colocados na sua coxa, perna e pé. Estes marcadores serão identificados por câmeras, estas câmeras não tem a capacidade de filmar a sua imagem, elas apenas identificam objetos que refletem a luz e em seguida enviam a informação para um computador, no qual serão feitas a análises da sua caminhada. Após, o Sr.(a) fará alguns testes em um aparelho que mede a força que o Sr.(a) é capaz de exercer em determinadas articulações do seu corpo (dinamômetro). Este aparelho será apresentado para o Sr.(a) pelo fisioterapeuta, assim como o detalhamento de todas as posições que serão feitos os testes. Será observado a sua capacidade de estender e flexionar o joelho. A duração estimada deste primeiro dia é de 4 horas.

Todas estas atividades: coleta de sangue, questionários e teste funcional, serão repetidas também na última sessão. A coleta de sangue será realizada também após 4 (quatro) semanas de sessões, então serão 3 (três) coletas de sangue durante a execução da pesquisa: no primeiro dia, após 4 (quatro) semanas e no último dia.

Na segunda sessão, o Sr.(a) realizará um treinamento de adaptação aos exercícios e aos aparelhos. Na terceira sessão, o Sr.(a) iniciará o treinamento que será repetido por mais 8 (oito) semanas. No início de cada treinamento, o Sr.(a) indicará a dor que está sentindo através de uma escala analógica visual, numerada de 0 a 10. Se a dor for maior que 4 (quatro) será utilizado um protocolo de alívio da dor com uso de ultrassom, ou laser, ou eletroestimulação. Se a dor reduzir o Sr.(a) poderá realizar o treinamento. O treinamento será um aquecimento na bicicleta ergométrica, exercícios de flexão e extensão do joelho e 
exercícios no aparelho que oferece resistência (leg press). Ao final de cada sessão o Sr.(a) realizará exercícios de alongamento e indicará novamente a dor na escala analógica visual.

O risco da participação na pesquisa é mínimo. Pode haver o desconforto de preencher os questionários por algum período de tempo e uma pequena dor da picada de agulha para a coleta de sangue e hematomas que irão desaparecer em poucos dias. Durante a execução dos exercícios pode aumentar um pouco a dor local inicialmente, que irá reduzir com as sessões. Em casos raros, podem ocorrer lesões musculoesqueléticas, traumatismos, arritmias cardíacas, respostas atípicas da pressão arterial e ataques cardíacos. Além da baixa frequência com que estes eventos ocorrem, caso aconteçam, o Sr.(a) será atendido prontamente no pronto-atendimento do Hospital Israelita Albert Einstein.

Após o término das sessões de fisioterapia, esperamos que o Sr.(a) consiga realizar as atividades diárias, como caminhar, subir e descer escadas sem dificuldades e sem dor.

\section{Esclarecemos que:}

*O Sr.(a) tem toda a liberdade de retirar o seu consentimento e deixar de participar do estudo a qualquer momento em que desejar, sem a necessidade de qualquer explicação e sem penalização alguma. Neste caso, o Sr.(a) poderá seguir com o tratamento recomendado pelo seu médico (quando for o caso).

*Todas as informações obtidas a seu respeito neste estudo, serão analisadas em conjunto com as de outros voluntários, não sendo divulgado a sua identificação ou de outros pacientes em nenhum momento.

*As informações produzidas neste estudo serão mantidas em lugar seguro, codificadas e a identificação só poderá ser realizada pela equipe do projeto, os dados e informações serão utilizados apenas para a pesquisa proposta. As amostras de sangue coletadas poderão ser armazenadas e disponibilizadas para uso geral em pesquisas associadas à osteoartrose. Caso o material venha a ser utilizado para publicação científica ou atividades didáticas, não serão utilizados nomes que possam vir a identificá-lo.

*Caso seja necessário, o Sr.(a) terá assistência permanente durante o estudo, ou mesmo após o término ou interrupção do estudo.

* Se ocorrer qualquer problema ou dano pessoal comprovadamente decorrente dos procedimentos ou tratamentos aos quais o Sr.(a) será submetido, lhe será garantido o direito a tratamento gratuito na Instituição e o Sr.(a) terá direito a indenização determinada por lei.

*A participação do Sr.(a) neste estudo é de caráter exclusivamente voluntário, ou seja, o Sr.(a) não receberá nenhuma compensação financeira relacionada à sua participação neste estudo. Da mesma forma, o Sr.(a) não terá nenhuma despesa pessoal em qualquer fase do estudo, incluindo exames e consultas. Durante o período de sua participação, se houver qualquer despesa adicional de sua parte em relação à condução ou alimentação, $\operatorname{Sr}(a)$. será reembolsado.

* A qualquer momento, se for de seu interesse, o Sr.(a) poderá ter acesso a todas as informações obtidas a seu respeito neste estudo, ou a respeito dos resultados gerais do estudo. 
* Caso o Sr.(a) desejar, ao final desta pesquisa poderá tomar conhecimento dos resultados do estudo:

( ) Desejo conhecer os resultados desta pesquisa.

( ) Não desejo conhecer os resultados desta pesquisa.

* Em qualquer etapa do estudo, o Sr.(a) terá acesso aos profissionais responsáveis pela pesquisa para esclarecimento de eventuais dúvidas. O principal investigador é o Dr. Mario Ferretti Filho que pode ser encontrado no endereço: Av. Albert Einstein, 627, CEP: 05651-901, Morumbi, Telefones: (11) 2151-1444 ou (11) 2151-1443. Se você tiver alguma consideração ou dúvida sobre a ética da pesquisa, entre em contato com o Comitê de Ética em Pesquisa (CEP) do Hospital Israelita Albert Einstein (11) - 2151-3729.

* Esse termo foi elaborado em duas vias devidamente assinadas, sendo que uma ficará com o Sr.(a) e a outra conosco.

Acredito ter sido suficientemente informado a respeito das informações que li ou que foram lidas para mim, descrevendo o estudo "Modulação de biomarcadores para osteoartrose após um programa de reabilitação". Eu discuti com o Dr. Mario Ferretti Filho sobre a minha decisão em participar nesse estudo. Ficaram claros para mim quais são os propósitos do estudo, os procedimentos a serem realizados, seus desconfortos e riscos, as garantias de confidencialidade e de esclarecimentos permanentes. Ficou claro também que minha participação é isenta de despesas e que tenho garantia do acesso a tratamento hospitalar quando necessário. Concordo voluntariamente em participar deste estudo e poderei retirar o meu consentimento a qualquer momento, antes ou durante o mesmo, sem penalidades ou prejuízo ou perda de qualquer benefício que eu possa ter adquirido, ou no meu atendimento neste Serviço.

Data:

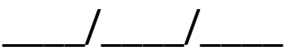

Nome do participante da pesquisa

Assinatura

"Declaro que obtive de forma apropriada e voluntária, o Consentimentos Livre e Esclarecido deste paciente (ou representante legal) para a participação neste estudo. Declaro ainda que me comprometo a cumpri todos os termos aqui descritos."

Data:

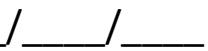


Anexo 2. Questionário Western Ontario e McMaster Universities (WOMAC)

\section{INSTRUÇÕES PARA OS PACIENTES}

Nas seções A, B e C as questões serăo feitas no seguinte formato, e você deverá responder marcando um "X" nos quadrados abaixo.

\section{NOTA:}

1. Se você colocar o "X" no quadrado da esquerda, ex.:

Nenhuma $\square \quad$ Leve $\square \quad$ Moderada $\square \quad$ Forte $\square \quad$ Muito forte

Você está indicando que não sente qualquer dor.

2. Se você colocar o " $X$ " no último quadrado da direita, ex.:

Nenhuma $\square \quad$ Leve $\square \quad$ Moderada $\square \quad$ Forte $\square \quad$ Muito forte

Você está indicando que sua dor é muito forte.

\section{Favor observe:}

a. Que quanto mais para a direita você colocar o " $\mathrm{X}$ ", mais dor você está sentindo.

b. Que quanto mais para a esquerda você colocar o "X", menos dor você está sentindo

c. Favor não colocar o " $\mathrm{X}$ " fora dos quadrados.

Você será solicitado a indicar neste tipo de escala a quantidade de dor, rigidez ou incapacidade física que você está sentindo. Favor lembrar que quanto mais para a direita você marcar o " $\mathrm{X}$ ", maior dor, rigidez ou incapacidade física você está sentindo. 


\section{SEÇÃO A}

\section{INSTRUÇÕES PARA OS PACIENTES}

A questão abaixo refere-se a intensidade da dor que você geralmente sente devido a artrose em seu joelho. Para cada situação, por favor marque a intensidade da dor sentida nas últimas 72 horas (favor marcar suas respostas com um "X").

\section{Questão:}

Quanta dor você tem?

1- Caminhando numa superfície plana.

Nenhuma $\square \quad$ Leve $\square \quad$ Moderada $\square \quad$ Forte $\square \quad$ Muito forte $\square$

2- Subindo ou descendo escadas.

Nenhuma $\square \quad$ Leve $\square \quad$ Moderada $\square \quad$ Forte $\square \quad$ Muito forte $\square$

3- A noite, deitado na cama.

Nenhuma $\square \quad$ Leve $\square \quad$ Moderada $\square \quad$ Forte $\square \quad$ Muito forte $\square$

4- Sentando ou deitando.

Nenhuma $\square \quad$ Leve $\square \quad$ Moderada $\square \quad$ Forte $\square \quad$ Muito forte $\square$

5- Ficando em pé.

Nenhuma $\square \quad$ Leve $\square \quad$ Moderada $\square \quad$ Forte $\square \quad$ Muito forte $\square$ 


\section{SEÇÃO B \\ INSTRUÇÕES PARA OS PACIENTES}

As seguintes questões referem-se a intensidade de rigidez articular (não a dor) que você vem sentindo em seu joelho nas últimas 72 horas. Rigidez é uma sensação de restrição ou lentidão na maneira como você move suas articulações (favor marcar suas respostas com um "X")

1- Qual a intensidade de sua rigidez logo após acordar de manhã? Nenhuma $\square \quad$ Leve $\square \quad$ Moderada $\square \quad$ Forte $\square \quad$ Muito forte $\square$

2- Qual a intensidade da rigidez após sentar-se, deitar-se ou descansar durante o dia?

Nenhuma $\square \quad$ Leve $\square \quad$ Moderada $\square \quad$ Forte $\square \quad$ Muito forte 


\section{SEÇÃO C \\ INSTRUÇÕES PARA OS PACIENTES}

As seguintes questões referem-se à sua atividade física. Isto quer dizer, sua habilidade para locomover-se e para cuidar-se. Para cada uma das seguintes atividades, por favor marque o grau da dificuldade que você vem sentindo nas últimas 72 horas devido a artrose em seu joelho (favor marcar suas respostas com um " $\mathrm{X}$ ").

Questão: Qual é o grau da dificuldade que você tem :

1- Descendo escadas.

Nenhuma $\square \quad$ Leve $\square \quad$ Moderada $\square \quad$ Forte $\square \quad$ Muito forte

2- Subindo escadas.

Nenhuma $\square \quad$ Leve $\square \quad$ Moderada $\square \quad$ Forte $\square \quad$ Muito forte

3- Levantando-se de uma cadeira.

Nenhuma $\square \quad$ Leve $\square \quad$ Moderada $\square \quad$ Forte $\square \quad$ Muito forte $\square$

4- Ficando em pé.

Nenhuma $\square \quad$ Leve $\square \quad$ Moderada $\square \quad$ Forte $\square \quad$ Muito forte

5- Curvando-se para tocar o chão.

Nenhuma $\square \quad$ Leve $\square \quad$ Moderada $\square \quad$ Forte $\square \quad$ Muito forte $\square$

6- Caminhando no plano.

Nenhuma $\square \quad$ Leve $\square \quad$ Moderada $\square \quad$ Forte $\square \quad$ Muito forte $\square$

7- Entrando ou saindo do carro.

Nenhuma $\square \quad$ Leve $\square \quad$ Moderada $\square \quad$ Forte $\square \quad$ Muito forte $\square$ 
8- Fazendo compras.

Nenhuma $\square \quad$ Leve $\square \quad$ Moderada $\square \quad$ Forte $\square \quad$ Muito forte $\square$

9- Colocando as meias / meias-calça.

Nenhuma $\square \quad$ Leve $\square \quad$ Moderada $\square \quad$ Forte $\square \quad$ Muito forte

10- Levantando da cama.

Nenhuma $\square \quad$ Leve $\square \quad$ Moderada $\square \quad$ Forte $\square \quad$ Muito forte

11- Tirando as meias / meias-calça.

Nenhuma $\square \quad$ Leve $\square \quad$ Moderada $\square \quad$ Forte $\square \quad$ Muito forte

12- Deitando na cama.

Nenhuma $\square \quad$ Leve $\square \quad$ Moderada $\square \quad$ Forte $\square \quad$ Muito forte

13- Entrando ou saindo do banho.

Nenhuma $\square \quad$ Leve $\square \quad$ Moderada $\square \quad$ Forte $\square \quad$ Muito forte $\square$

14- Sentando-se.

Nenhuma $\square \quad$ Leve $\square \quad$ Moderada $\square \quad$ Forte $\square \quad$ Muito forte

15- Sentando-se ou levantando-se do vaso sanitário.

Nenhuma $\square \quad$ Leve $\square \quad$ Moderada $\square \quad$ Forte $\square \quad$ Muito Forte $\square$

16- Fazendo tarefas domésticas pesadas.

Nenhuma $\square \quad$ Leve $\square \quad$ Moderada $\square \quad$ Forte $\square \quad$ Muito forte

17- Fazendo tarefas domésticas leves.

Nenhuma $\square \quad$ Leve $\square \quad$ Moderada $\square \quad$ Forte $\square \quad$ Muito forte

Fonte: Fernandes MI. Tradução e validação do questionário de qualidade de vida específico para osteoartrose WOMAC (Western Ontario and McMaster Universities) para a língua portuguesa. [dissertação]. [São Paulo]: Universidade Federal de São Paulo; 2002. ${ }^{(39)}$ 
Anexo 3. Questionário relacionado com a saúde e qualidade de vida (EuroQol EQ-

$5 \mathrm{D}-3 \mathrm{~L})$
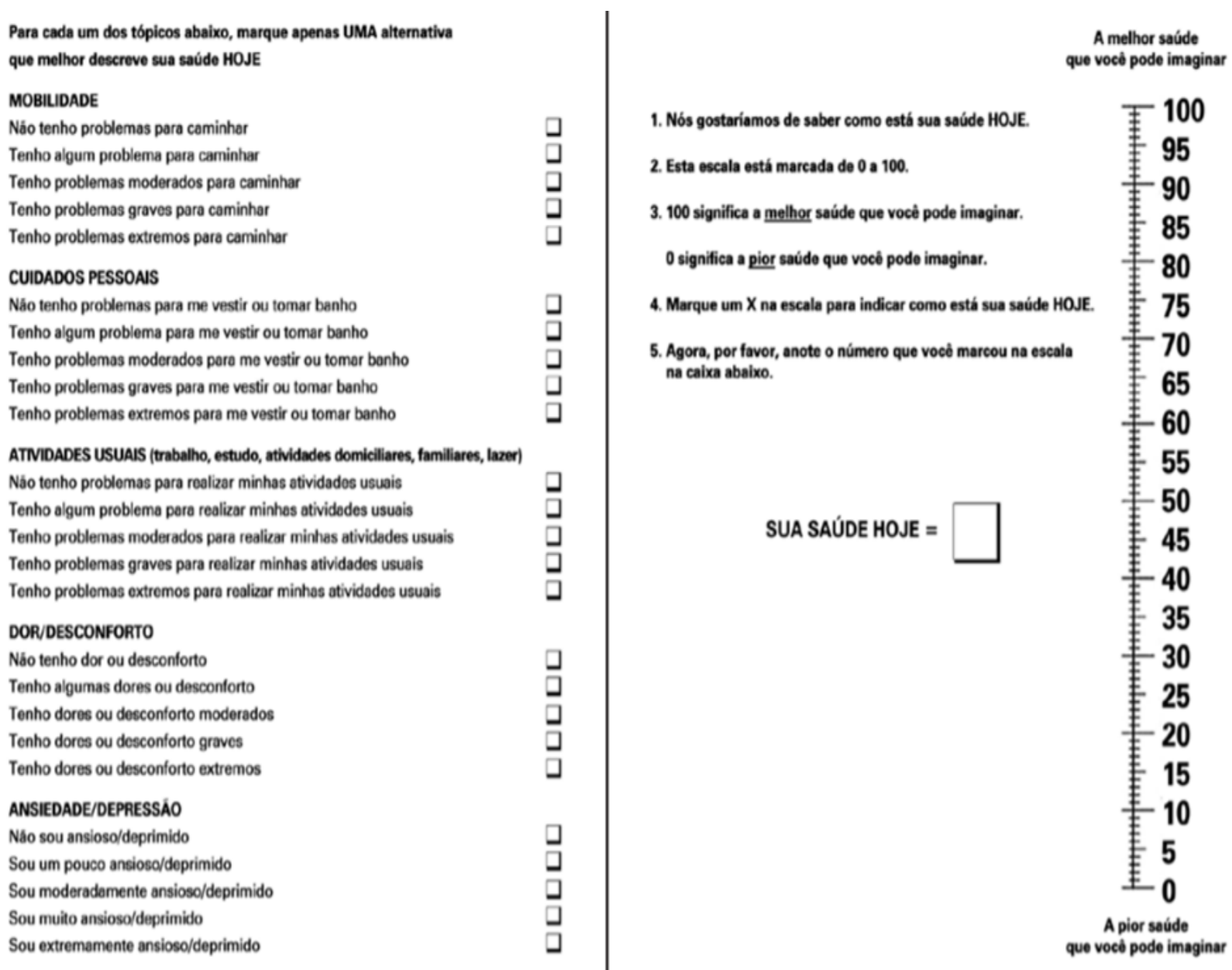

Fonte: Menezes RM,Andrade MV, Noronha QVMS, Kind P.EQ-5D-3L as a health measure of Brazilian adult population. Qual Life Res. 2015; 24:2761-76. ${ }^{(40)}$ 
Anexo 4. Escala Visual Analógica de Dor (EVA)

Em uma escala de 0 a 10, sendo 0 nenhuma dor e 10 a pior dor imaginável, por favor marque com um x a nota para sua dor no joelho nos últimos sete dias. Escolha apenas números inteiros. Não considere outras dores.

\begin{tabular}{|r|r|r|r|r|r|r|r|r|r|r|}
\hline $\mathbf{0}$ & $\mathbf{1}$ & $\mathbf{2}$ & $\mathbf{3}$ & $\mathbf{4}$ & $\mathbf{5}$ & $\mathbf{6}$ & $\mathbf{7}$ & $\mathbf{8}$ & $\mathbf{9}$ & $\mathbf{1 0}$ \\
\hline \\
$\mathrm{SEMM}$ \\
$\mathrm{DOR}$
\end{tabular}

Fonte: Costa LO, Maher CG, Latimer J, Ferreira PH, Ferreira ML, Pozzi GC, Freitas LM. Clinimetric testing of three self-report outcome measures for low back pain patients in Brazil: which one is the best? Spine. 2008;33(22):2459-63. ${ }^{(41)}$ 


\section{REFERÊNCIAS}

1. Cooper C, Javaid MK, Arden N. Epidemiology of osteoarthritis. In: Arden N, Blanco F, Cooper C, Guermazi A, Hayashi D, Hunter D, et al. Atlas of osteoarthritis. London: Springer Healthcare; 2014. p. 21-36.

2. Osteoarthritis Research Society International. Standardization of osteoarthritis definitions [Internet]. Mount Laurel: Osteoarthritis Research Society International; 2013 [cited 2015 Apr 9]. Available from: https://oarsi.org/research/standardization-osteoarthritis-definitions

3. Grynpas MD, Alpert B, Katz I, Lieberman I, Pritzker KP. Subchondral bone in osteoarthritis. Calcif Tissue Int. 1991;49(1):20-6.

4. Felson DT, Zhang Y. An update on the epidemiology of knee and hip osteoarthritis with a view to prevention. Arthritis Rheum. 1998;41(8):1343-55.

5. Jordan KM, Arden NK, Doherty M, Bannwarth B, Bijlsma JW, Dieppe P, et al.; Standing Committee for International Clinical Studies Including Therapeutic Trials ESCISIT. EULAR Recommendations 2003: an evidence based approach to the management of knee osteoarthritis. Ann Rheum Dis. 2003;62(12):1145-55.

6. Wenham CY, Conaghan PG. New horizons in osteoarthritis. Age Ageing. 2013;42(3):272-8.

7. Weintein SL, Jacobs JJ, Goldberg MJ. Osteoarthritis of the knee. N Engl J Med. 2006;354(23):2508-9; author reply 2508-9.

8. Kapoor M, Martel-Pelletier J, Lajeunesse D, Pelletier JP, Fahmi H. Role of proinflammatory cytokines in the pathophysiology of osteoarthritis. Nat Rev Rheumatol. 2011;7(1):33-42.

9. Cross M, Smith E, Hoy D, Nolte S, Ackerman I, Fransen M, et al. The global burden of hip and knee osteoarthritis: estimates from the global burden of disease 2010 study. Ann Rheum Dis. 2014;73(7):1323-30.

10. Vos T, Abajobir AA, Abate KH, Abbafati C, Abbas KM, Abd-Allah F, et al.; GBD 2016 Disease and Injury Incidence and Prevalence Collaborators. Global, regional, and national incidence, prevalence, and years lived with disability for 328 diseases and injuries for 195 countries, 1990-2016: a systematic analysis for the Global Burden of Disease Study 2016. Lancet. 2017;390(10100):1211-59.

11. Das SK, Farooqi A. Osteoarthritis. Best Pract Res Clin Rheumatol. 2008;22(4):657-75.

12. Senna ER, De Barros AL, Silva EO, Costa IF, Pereira LV, Ciconelli RM, et al. Prevalence of rheumatic diseases in Brazil: a study using the COPCORD approach. J Rheumatol. 2004;31(3):594-7.

13. World Health Organization. Chronic rheumatic conditions [Internet]. Geneva: World Health Organization; c2020 [cited 2014 Jun 1]. Available from:

https://www.who.int/chp/topics/rheumatic/en

14. Pintan GF, de Oliveira AS Jr, Lenza M, Antonioli E, Ferretti M. Update on biological therapies for knee injuries: osteoarthritis. Curr Rev Musculoskelet Med. 2014;7(3):263-9.

15. Hochberg MC, Altman RD, April KT, Benkhalti M, Guyatt G, McGowan J, et al.; American College of Rheumatology. American College of Rheumatology 2012 recommendations for the use of nonpharmacologic and pharmacologic therapies in osteoarthritis of the hand, hip, and knee. Arthritis Care Res (Hoboken). 2012;64(4):465-74. 
16. McAlindon TE, Bannuru RR, Sullivan MC, Arden NK, Berenbaum F, Bierma-Zeinstra SM, et al. OARSI guidelines for the non-surgical management of knee osteoarthritis. Osteoarthritis Cartilage. 2014;22(3):363-88.

17. Quicke JG, Foster NE, Thomas MJ, Holden MA. Is Iong-term physical activity safe for older adults with knee pain? A systematic review. Osteoarthritis Cartilage. 2015;23(9):1445-56.

18. Hurley MV, Walsh NE, Mitchell HL, Pimm TJ, Patel A, Williamson E, et al. Clinical effectiveness of a rehabilitation program integrating exercise, self-management, and active coping strategies for chronic knee pain: a cluster randomized trial. Arthritis Rheum. 2007;57(7):1211-9.

19. Fernandes L, Hagen KB, Bijlsma JW, Andreassen O, Christensen P, Conaghan PG, et al.; European League Against Rheumatism (EULAR). EULAR recommendations for the nonpharmacological core management of hip and knee osteoarthritis. Ann Rheum Dis. 2013;72(7):1125-35.

20. Verhagen AP, Ferreira M, Reijneveld-van de Vendel EA, Teirlinck $\mathrm{CH}$, Runhaar J, van Middelkoop M, et al. Do we need another trial on exercise in patients with knee osteoarthritis? No new trials on exercise in knee OA. Osteoarthritis Cartilage. 2019;27(9):1266-9.

21. Minshull C, Gleeson N. Considerations of the principles of resistance training in exercise studies for the management of knee osteoarthritis: a systematic review. Arch Phys Med Rehabil. 2017;98(9):1842-51.

22. Davis AM, MacKay C. Osteoarthritis year in review: outcome of rehabilitation. Osteoarthritis Cartilage. 2013;21(10):1414-24.

23. Jonsson T, Ekvall Hansson E, Thorstensson CA, Eek F, Bergman P, Dahlberg LE. The effect of education and supervised exercise on physical activity, pain, quality of life and selfefficacy - an intervention study with a reference group. BMC Musculoskelet Disord. 2018;19(1):198.

24. Bannuru RR, Osani MC, Vaysbrot EE, Arden NK, Bennell K, Bierma-Zeinstra SM, et al. OARSI guidelines for the non-surgical management of knee, hip, and polyarticular osteoarthritis. Osteoarthritis Cartilage. 2019;27(11):1578-89.

25. Jamtvedt G, Dahm KT, Christie A, Moe RH, Haavardsholm E, Holm I, et al. Physical therapy interventions for patients with osteoarthritis of the knee: an overview of systematic reviews. Phys Ther. 2008;88(1):123-36.

26. Goh SL, Persson MS, Stocks J, Hou Y, Welton NJ, Lin J, et al. Relative efficacy of different exercises for pain, function, performance and quality of life in knee and hip osteoarthritis: systematic review and network meta-analysis. Sports Med. 2019;49(5):743-61.

27. Fransen M, McConnell S, Harmer AR, Van der Esch M, Simic M, Bennell KL. Exercise for osteoarthritis of the knee: a Cochrane systematic review. Br J Sports Med. 2015;49(24):15547.

28. Patel S, Heine PJ, Ellard DR, Underwood M. Group exercise and self-management for older adults with osteoarthritis: a feasibility study. Prim Health Care Res Dev. 2016;17(3):25264.

29. Golightly YM, Allen KD, Caine DJ. A comprehensive review of the effectiveness of different exercise programs for patients with osteoarthritis. Phys Sportsmed. 2012;40(4):52-65.

30. Royal Australian College of General Practitioners. Guideline for the management of knee and hip osteoarthritis [Internet]. 2nd ed. East Melbourne: The Royal Australian College of General Practitioners; 2018 [cited 2018 Jun 1]. Available from: 
https://www.racgp.org.au/FSDEDEV/media/documents/Clinical\%20Resources/Guidelines/Join t\%20replacement/Guideline-for-the-management-of-knee-and-hip-OA-2nd-edition.pdf

31. Lambova S. Exercise programmes for osteoarthritis with different localization. Curr Rheumatol Rev. 2018;14(2):123-30.

32. Collins NJ, Hart HF, Mills KA. Osteoarthritis year in review 2018: rehabilitation and outcomes. Osteoarthritis Cartilage. 2019;27(3):378-91.

33. Oiestad BE, Juhl CB, Eitzen I, Thorlund JB. Knee extensor muscle weakness is a risk factor for development of knee osteoarthritis. A systematic review and meta-analysis. Osteoarthritis Cartilage. 2015;23(2):171-7.

34. Hislop AC, Collins NJ, Tucker K, Deasy M, Semciw Al. Does adding hip exercises to quadriceps exercises result in superior outcomes in pain, function and quality of life for people with knee osteoarthritis? A systematic review and meta-analysis. Br J Sports Med. 2020;54(5):263-71.

35. Collins NJ, Hart HF, Mills KAG. OARSI year in review 2018: rehabilitation and outcomes. Osteoarthritis and Cartilage. 2019;27: 378-391.

36. Ratamess NA, Alvar BA, Evetoch TK, Housh TJ, Kibler WB, Kraemer WJ, et al.; American College of Sports Medicine. American College of Sports Medicine position stand. Progression models in resistance training for healthy adults. Med Sci Sports Exerc. 2009;41(3):687-708.

37. Garber CE, Blissmer B, Deschenes MR, Franklin BA, Lamonte MJ, Lee IM, et al.; American College of Sports Medicine. American College of Sports Medicine position stand. Quantity and quality of exercise for developing and maintaining cardiorespiratory, musculoskeletal, and neuromotor fitness in apparently healthy adults: guidance for prescribing exercise. Med Sci Sports Exerc. 2011;43(7):1334-59.

38. Altman R, Asch E, Bloch D, Bole G, Borenstein D, Brandt K, et al.; Diagnostic and Therapeutic Criteria Committee of the American Rheumatism Association. Development of criteria for the classification and reporting of osteoarthritis. Classification of osteoarthritis of the knee. Arthritis Rheum. 1986;29(8):1039-49.

39. Fernandes MI. Tradução e validação do questionário de qualidade de vida específico para osteoartrose WOMAC (Western Ontario and McMaster Universities) para a língua portuguesa. [dissertação]. [São Paulo]: Universidade Federal de São Paulo; 2002.

40. Menezes RM,Andrade MV, Noronha QVMS, Kind P.EQ-5D-3L as a health measure of Brazilian adult population. Qual Life Res. 2015; 24:2761-2776.

41. Costa LO, Maher CG, Latimer J, Ferreira PH, Ferreira ML, Pozzi GC, Freitas LM. Clinimetric testing of three self-report outcome measures for low back pain patients in Brazil: which one is the best? Spine. 2008;33(22):2459-63.

42. Podsiadlo D, Richardson S. The timed "Up \& Go": a test of basic functional mobility for frail elderly persons. J Am Geriatr Soc. 1991;39(2):142-8.

43. Dvir Z. Isokinetics: muscle testing. Interpretation and clinical applications. 2nd ed. Edinburgh: Churchill Livingstone, 2004.

44. Coombs R, Garbutt G. Developments in the use of the hamstring/quadriceps ratio for the assessment of muscle balance. J Sports Sci Med. 2002;1(3):56-62.

45. Demura S, Nagasawa Y. Relations between perceptual and physiological response during incremental exercise followed by an extended bout of submaximal exercise on a cycle ergometer. Percept Mot Skills. 2003;96(2):653-63.

46. Altman DG. Practical statistics for medical research. London: Chapman \& Hall/CRC; 1991. 
47. Faraway JJ. Extending the linear model with R: generalized linear, mixed effects and nonparametric regression models. Boca Raton: Chapman \& Hall/CRC; 2006.

48. Hosmer DW, Lemeshow S. Applied logistic regression. 2nd ed. New York: John Wiley \& Sons; 2004.

49. Williams VJ, Piva SR, Irrgang JJ, Crossley C, Fitzgerald GK. Comparison of reliability and responsiveness of patient-reported clinical outcome measures in knee osteoarthritis rehabilitation. J Orthop Sports Phys Ther. 2012;42(8):716-23.

50. De Rooij M, van der Leeden M, Cheung J, van der Esch M, Häkkinen A, Haverkamp D, et al. Effectiveness of tailored exercise therapy in patients with knee osteoarthritis and comorbidity: a randomized controlled trial. Osteoarthritis Cartilage. 2016;24:S466-7.

51. Srikanth VK, Fryer JL, Zhai G, Winzenberg TM, Hosmer D, Jones G. A meta-analysis of sex differences prevalence, incidence and severity of osteoarthritis. Osteoarthritis Cartilage. 2005;13(9):769-81.

52. Reid KF, Price LL, Harvey WF, Driban JB, Hau C, Fielding RA, et al. Muscle power is an independent determinant of pain and quality of life in knee osteoarthritis. Arthritis Rheumatol. 2015;67(12):3166-73.

53. Yilmaz M, Sahin M, Algun ZC. Comparison of effectiveness of the home exercise program and the home exercise program taught by physiotherapist in knee osteoarthritis. J Back Musculoskeletal Rehabil. 2019;32(1):161-9.

54. Brosseau L, Taki J, Desjardins B, Thevenot O, Fransen M, Wells GA, et al. The Ottawa panel clinical practice guidelines for the management of knee osteoarthritis. Part three: aerobic exercise programs. Clin Rehabil. 2017;31(5):612-24.

55. Caneiro JP, O'Sullivan PB, Roos EM, Smith AJ, Choong P, Dowsey M, et al. Three steps to changing the narrative about knee osteoarthritis care: a call to action. Br J Sports Med. 2020;54(5):256-8.

56. Runhaar J, Luijsterburg P, Dekker J, Bierma-Zeinstra SM. Identifying potential working mechanisms behind the positive effects of exercise therapy on pain and function in osteoarthritis; a systematic review. Osteoarthritis Cartilage. 2015;23(7):1071-82.

57. Tanaka R, Ozawa J, Kito N, Moriyama H. Efficacy of strengthening or aerobic exercise on pain relief in people with knee osteoarthritis: a systematic review and meta-analysis of randomized controlled trials. Clin Rehabil. 2013;27(12):1059-71.

58. Jansen MJ, Viechtbauer W, Lenssen AF, Hendriks EJ, de Bie RA. Strength training alone, exercise therapy alone, and exercise therapy with passive manual mobilisation each reduce pain and disability in people with knee osteoarthritis: a systematic review. J Physiother. 2011;57(1):11-20.

59. Anwer S, Alghadir A. Effect of isometric quadriceps exercise on muscle strength, pain, and function in patients with knee osteoarthritis: a randomized controlled study. J Phys Ther Sci. 2014;26(5):745-8.

60. Bokaeian HR, Bakhtiary AH, Mirmohammadkhani M, Moghimi J. Quadriceps strengthening exercises may not change pain and function in knee osteoarthritis. J Bodyw Mov Ther. 2018;22(2):528-33.

61. Farr J II, Miller LE, Block JE. Quality of life in patients with knee osteoarthritis: a commentary on nonsurgical and surgical treatments. Open Orthop J. 2013;7(1):619-23. 
62. Wu M, Brazier JE, Kearns B, Relton C, Smith C, Cooper CL. Examining the impact of 11 long-standing health conditions on health-related quality of life using the EQ-5D in a general population sample. Eur J Health Econ. 2015;16(2):141-51.

63. Kiadaliri AA, Lamm CJ, de Verdier MG, Engstrom G, Turkiewicz A, Lohmander LS, et al. Association of knee pain and different definitions of knee osteoarthritis with health-related quality of life: a population-based cohort study in southern Sweden. Health Qual Life Outcomes. 2016;14(1):121.

64. Marconcin P, Espanha M, Teles J, Bento P, Campos P, Andre R, et al. A randomized controlled trial of a combined self-management and exercise intervention for elderly people with osteoarthritis of the knee: the PLE2NO program. Clin Rehabil. 2018;32(2):223-32.

65. Kurtais Y, Oztuna D, Kuçukdeveci AA, Kutlay S, Hafiz M, Tennant A. Reliability, construct validity and measurement potential of the ICF comprehensive core set for osteoarthritis. BMC Musculoskelet Disord. 2011;12(1):255.

66. Hauber AB, Arden NK, Mohamed AF, Johnson FR, Peloso PM, Watson DJ, et al. A discrete-choice experiment of United Kingdom patients' willingness to risk adverse events for improved function and pain control in osteoarthritis. Osteoarthritis Cartilage. 2013;21(2):28997.

67. Guccione AA, Felson DT, Anderson JJ, Anthony JM, Zhang Y, Wilson PW, et al. The effects of specific medical conditions on the functional limitations of elders in the Framingham Study. Am J Public Health. 1994;84(3):351-8.

68. Lange AK, Vanwanseele B, Fiatarone Singh MA. Strength training for treatment of osteoarthritis of the knee: a systematic review. Arthritis Rheum. 2008;59(10):1488-94.

69. Alghadir A, Anwer S, Brismée JM. The reliability and minimal detectable change of Timed Up and Go test in individuals with grade 1-3 knee osteoarthritis. BMC Musculoskelet Disord. 2015;16(1):174.

70. de Rezende MU, de Farias FE, da Silva CA, Cernigoy $\mathrm{CH}$, de Camargo OP. Objective functional results in patients with knee osteoarthritis submitted to a 2-day educational programme: a prospective randomised clinical trial. BMJ Open Sport Exerc Med. 2017;2(1):e000200.

71. Oliveira AM, Peccin MS, Silva KN, Teixeira LE, Trevisani VF. Impact of exercise on the functional capacity and pain of patients with knee osteoarthritis: a randomized clinical trial. Rev Bras Reumatol. 2012;52(6):870-82.

72. Mayer F, Horstmann T, Kranenberg U, Rocker K, Dickhuth HH. Reproducibility of isokinetic peak torque and angle at peak torque in the shoulder joint. Int J Sports Med. 1994;15(Suppl 1):S26-31.

73. Hall M, Hinman RS, van der Esch M, van der Leeden M, Kasza J, Wrigley TV, et al. Is the relationship between increased knee muscle strength and improved physical function following exercise dependent on baseline physical function status? Arthritis Res Ther. 2017;19(1):271.

74. Hakkinen K, Kallinen M, Linnamo V, Pastinen UM, Newton RU, Kraemer WJ. Neuromuscular adaptations during bilateral versus unilateral strength training in middle-aged and elderly men and women. Acta Physiol Scand. 1996;158(1):77-88.

75. Bamaç B, Çolak T, Ozbek A, Çolak S, Cinel Y, Yenigun O. Isokinetic performance in elite volleyball and basketball players. Kinesiology. 2008;40(2):182-8.

76. Mau-Moeller A, Gube M, Felser S, Feldhege F, Weippert M, Husmann F, et al. Intrarater reliability of muscle strength and hamstring to quadriceps strength imbalance ratios during 
concentric, isometric, and eccentric maximal voluntary contractions using the isoforce dynamometer. Clin J Sport Med. 2019;29(1):69-77.

77. Beckwee D, Vaes P, Cnudde M, Swinnen E, Bautmans I. Osteoarthritis of the knee: why does exercise work? A qualitative study of the literature. Ageing Res Rev. 2013;12(1):226-36.

78. Juhl C, Christensen R, Roos EM, Zhang W, Lund H. Impact of exercise type and dose on pain and disability in knee osteoarthritis: a systematic review and meta-regression analysis of randomized controlled trials. Arthritis Rheumatol. 2014;66(3):622-36. 


\section{Abstract}

Introduction: Osteoarthritis is mainly related to aging and causes joint cartilage degeneration, joint pain, and consequently locomotor disability, which constitutes an important public health problem. There is no cure or disease-modifying drugs available to treat, reverse or prevent osteoarthritis progression. Exercise and physical activity combined with patient education have shown effective results as first treatments to reduce knee pain and improve physical function and quality of life. Purpose: To evaluate the simplified conservative treatment regarding pain, function, muscle strength and quality of life for three muscle groups among patients with knee osteoarthritis. Methods: This was a prospective cohort study composed of participants with knee osteoarthritis. We included men and women aged 45 to 65 years who were recruited from January 2017 to January 2019. Participants underwent a simplified exercise protocol for eight weeks including three sessions per week. The protocol consisted of three resistance exercises: leg press, extension and knee flexion. Outcomes were assessed using the Western Ontario MacMaster University (WOMAC) osteoarthritis functional scale, the quality of life scale (EQ-5D-3L), the pain scale Visual Analog-Pain Scale (VAS) and the functional test - Timed Up and Go (TUG) and the muscle strength assessments. Outcomes were collected before and after the rehabilitation protocol. Results: Of the 47 participants, 30 women (63.8\%) with mean age of 55.4 years, body mass index of $29.3 \mathrm{~kg} / \mathrm{m}^{2}$, Kellgren-Lawrence's grade 2 (68.1\%) and $3(31.9 \%)$ completed the study. Participants showed improvement in pain by VAS, stiffness and function by the WOMAC scale, and also improvement in pain perception by VAS, health status scores by EQ-5D-3L, and mobility ability by TUG. The assessment of isometric strength of extension and flexion muscles of lower limbs showed a peak torque at the end of the protocol. In the evaluation of the isometric force contractile index a significant difference was observed in flexion on both sides and extension on the side not affected by the osteoarthritis. In the evaluation of the isokinetic peak torque there was a significant difference in flexion on both sides. We did not observe evidence of association in the variability $\geq 8.8 \%$ in the WOMAC score. This score was standardized as an indication of clinical improvement, gender variability, age, body mass index, arthritis grade, EQ-5D-3L and VAS scores, therefore, suggesting that the protocol can be used to treat both men and women aged 
45 to 65 years. Conclusions: The simplified conservative treatment for strengthening of three muscle groups for patients with knee osteoarthritis was effective in improving pain, function, muscle strength and quality of life.

ClinicalTrials.gov Identifier: NCT 02964624.

Keywords: Osteoarthritis; Exercise therapy; Pain measurement, Quality of life; Muscle strength 


\section{Apêndices}

Apêndice 1. Folha para Informações Sociodemográficas

\section{INFORMAÇÕES PARA CONTATO}

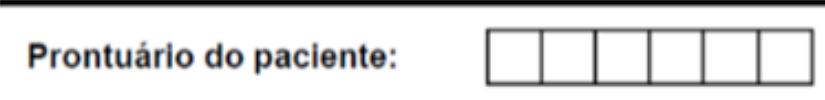

Nome do Paciente (utilize letra de forma, legivel)

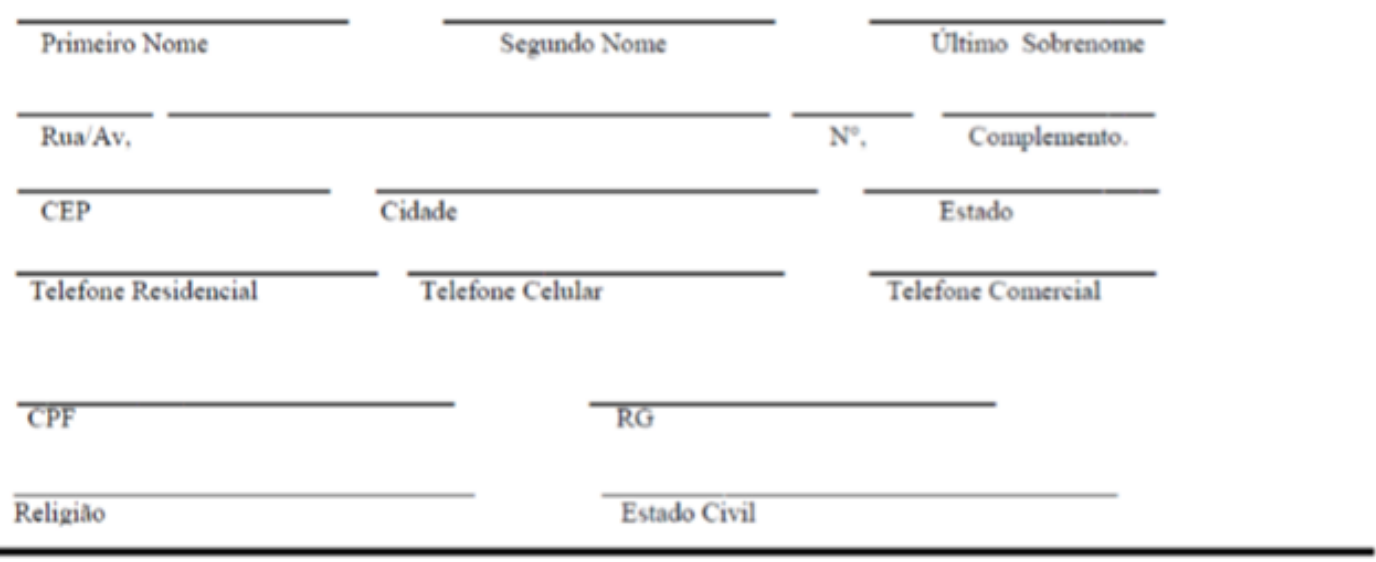

Familiar ou amigo do paciente (familiar próximo ou amigo e que năo vive com o paciente)

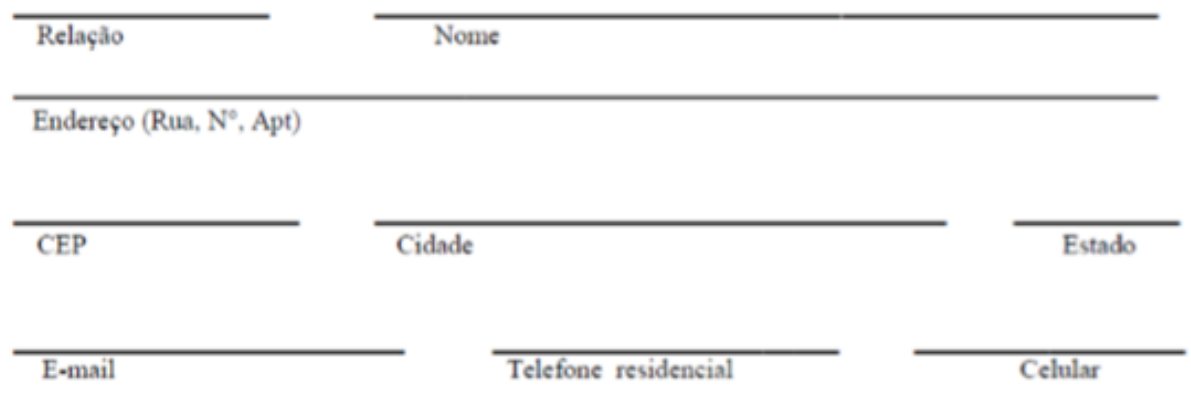


Apêndice 2. Ficha de Controle de Avaliação e Tratamento

\begin{tabular}{|l|l|l|}
\hline \multicolumn{3}{|c|}{ DADOS GERAIS } \\
\hline Paciente: & e-mail: & Nascimento: \\
\hline Pront.: & MI dominante: D( ) E( ) & Joelho mais acometido: D() E() \\
\hline Tel/Cel: &
\end{tabular}

MI - Membro Inferior

\begin{tabular}{|c|c|c|}
\hline \multicolumn{3}{|c|}{ Controle de Visitas - Pro } \\
\hline \multicolumn{3}{|c|}{ Bloco 1 } \\
\hline Visita & Data Prevista & Data Realizada \\
\hline 1 & & \\
\hline 2 & & \\
\hline 3 & & \\
\hline 4 & & \\
\hline 5 & & \\
\hline 6 & & \\
\hline 7 & & \\
\hline 8 & & \\
\hline 9 & & \\
\hline 10 & & \\
\hline 11 & & \\
\hline 12 & & \\
\hline & & \\
\hline & & \\
\hline
\end{tabular}

\begin{tabular}{|l|l|}
\hline \multicolumn{2}{|c|}{ Cargas - Bloco 1 } \\
\hline Cicloergômetro (Estágio) & \\
\hline Leg Press (Kg) & \\
\hline Cadeira Extensora (Kg) & \\
\hline Cadeira Flexora (Kg) & \\
\hline
\end{tabular}

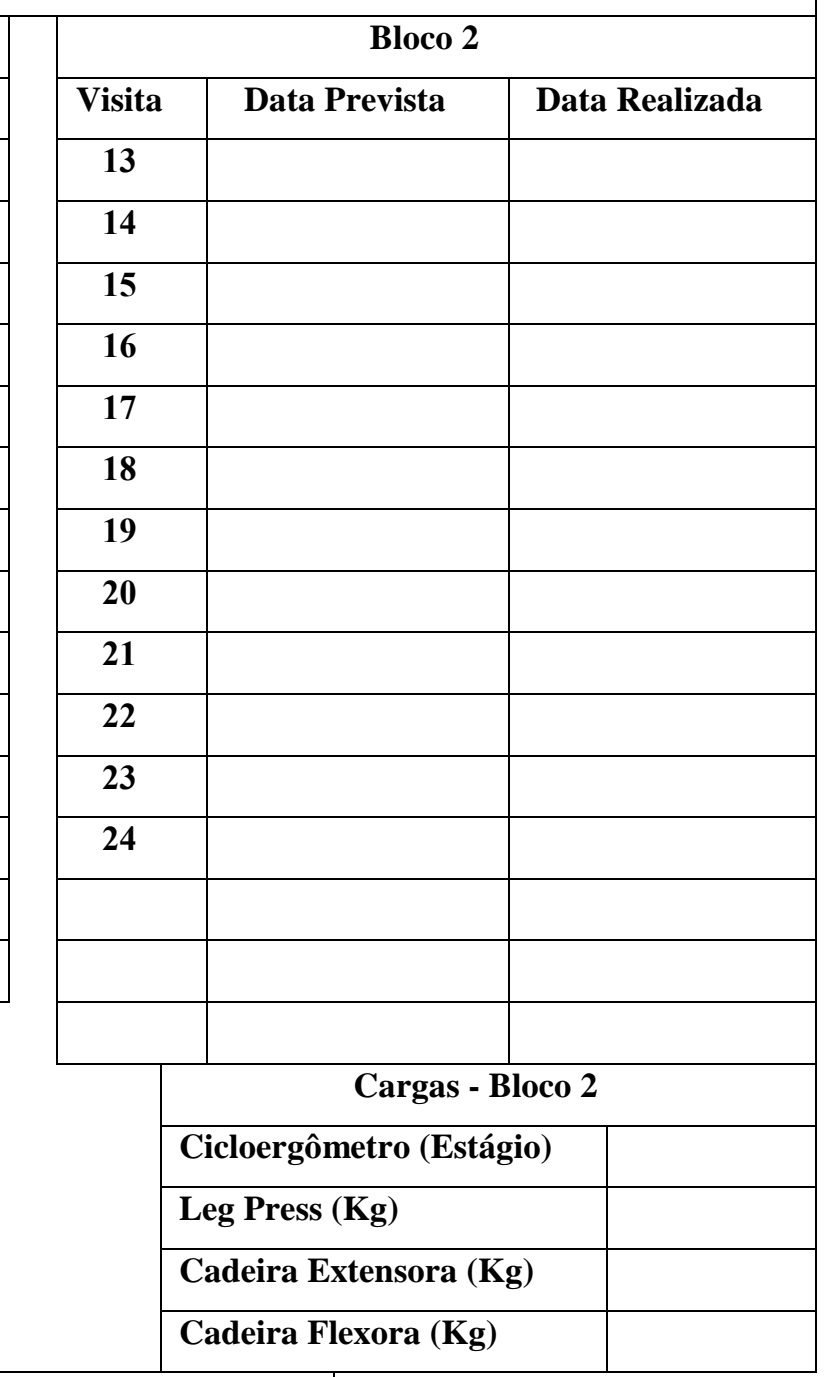

\begin{tabular}{|l|l|l|l|}
\hline \multicolumn{3}{|c|}{ Posicionamento no Aparelho } \\
\hline Cicloergômetro & & & \\
\hline Leg Press (Kg) & & & \\
\hline Cadeira Extensora (Kg) & & & \\
\hline Cadeira Flexora (Kg) & & & \\
\hline
\end{tabular}

Dados Antropométricos 


\begin{tabular}{|l|l|l|}
\hline & Inicial & Final \\
\hline Altura (cm) & & \\
\hline Peso $(\mathbf{K g})$ & & \\
\hline IMC $\left(\mathbf{K g} / \mathbf{c m}^{2}\right)$ & & \\
\hline Cintura (cm) & & \\
\hline Quadril (cm) & & \\
\hline Cintura/Quadril & & \\
\hline
\end{tabular}

\begin{tabular}{|l|l|l|l|l|l|l|l|l|l|l|l|l|}
\hline \multicolumn{10}{|c|}{ Escala de Graduação Numérica de Dor (EGN) - Bloco 1 } \\
\hline Sessão & $\mathbf{1}$ & $\mathbf{2}$ & $\mathbf{3}$ & $\mathbf{4}$ & $\mathbf{5}$ & $\mathbf{6}$ & $\mathbf{7}$ & $\mathbf{8}$ & $\mathbf{9}$ & $\mathbf{1 0}$ & $\mathbf{1 1}$ & $\mathbf{1 2}$ \\
\hline $\begin{array}{l}\text { EGN } \\
\text { Inicial }\end{array}$ & & & & & & & & & & & & \\
\hline $\begin{array}{l}\text { EGN } \\
\text { Analgesia } \\
*\end{array}$ & & & & & & & & & & & & \\
\hline
\end{tabular}

*Apenas quando for realizada sessão de analgesia.

\begin{tabular}{|l|l|l|l|l|l|l|l|l|l|l|l|l|}
\hline \multicolumn{10}{|c|}{ Escala de Graduação Numérica de Dor (EGN) - Bloco 2 } \\
\hline Sessão & 13 & 14 & 15 & 16 & 17 & 18 & 19 & 20 & 21 & 22 & 23 & 24 \\
\hline $\begin{array}{l}\text { EGN } \\
\text { Inicial }\end{array}$ & & & & & & & & & & & & \\
\hline $\begin{array}{l}\text { EGN } \\
\text { Analgesia } \\
*\end{array}$ & & & & & & & & & & & & \\
\hline
\end{tabular}

*Apenas quando for realizada sessão de analgesia.

\begin{tabular}{|c|c|c|c|c|}
\hline \multicolumn{5}{|c|}{ Timed Up and Go (TUG) } \\
\hline & \multicolumn{2}{|c|}{ Inicial } & \multicolumn{2}{c|}{ Final } \\
\hline $\begin{array}{c}\text { Tentativ } \\
\text { a }\end{array}$ & L. Direito & L. & L. Direito & L. \\
& & Esquerdo & & Esquerdo \\
\hline $\mathbf{1}$ & & & & \\
\hline $\mathbf{2}$ & & & & \\
\hline 3 & & & & \\
\hline Média & & & & \\
\hline
\end{tabular}

L.- Lado da rotação.

\begin{tabular}{|c|c|c|c|c|c|c|c|}
\hline \multicolumn{9}{|c|}{ Teste Incremental Cicloergômetro } \\
\hline \multicolumn{2}{|c|}{} & \multicolumn{5}{|c|}{ Período do Treinamento } \\
\cline { 3 - 9 } & \multicolumn{2}{|c|}{ Inicial } & Intermediário & \multicolumn{2}{c|}{ Final } \\
\hline Tempo & Estágio & Borg & FC & Borg & FC & Borg & FC \\
\hline 0' & Basal & & & & & & \\
\hline
\end{tabular}




\begin{tabular}{|c|c|l|l|l|l|l|l|}
\hline $\mathbf{5}^{\prime}$ & $\mathbf{1}$ & & & & & & \\
\hline $\mathbf{8}^{\prime}$ & $\mathbf{1}$ & & & & & & \\
\hline $\mathbf{1 1} \mathbf{\prime}^{\prime}$ & $\mathbf{2}$ & & & & & & \\
\hline $\mathbf{1 4}$ & $\mathbf{3}$ & & & & & & \\
\hline $\mathbf{1 7}$ & $\mathbf{4}$ & & & & & & \\
\hline $\mathbf{2 0} \mathbf{y}^{\prime}$ & $\mathbf{5}$ & & & & & & \\
\hline
\end{tabular}

FC - Frequência cardíaca.

\begin{tabular}{|c|c|c|c|c|c|c|}
\hline \multicolumn{7}{|c|}{ Teste de 1RM Leg Press } \\
\hline & \multicolumn{6}{|c|}{ Período do Treinamento } \\
\hline & \multicolumn{2}{|c|}{ Inicial } & \multicolumn{2}{|c|}{ Intermediário } & \multicolumn{2}{|c|}{ Final } \\
\hline Tentativa & $\begin{array}{c}\text { Carga } \\
(\mathrm{Kg})\end{array}$ & V/NV & Carga $(\mathrm{Kg})$ & $\mathbf{V} / \mathbf{N V}$ & $\begin{array}{c}\text { Carga } \\
(\mathrm{Kg})\end{array}$ & $\begin{array}{l}\mathbf{V} / \mathbf{N V} \\
\end{array}$ \\
\hline 1 & & & & & & \\
\hline 2 & & & & & & \\
\hline 3 & & & & & & \\
\hline 4 & & & & & & \\
\hline 5 & & & & & & \\
\hline 1RM & & & & & & \\
\hline
\end{tabular}

V- Tentativa válida; NV - tentativa não válida.

\begin{tabular}{|c|c|c|c|c|c|c|}
\hline \multicolumn{7}{|c|}{ Teste de 1RM Cadeira Extensora } \\
\hline & \multicolumn{6}{|c|}{ Período do Treinamento } \\
\hline & \multicolumn{2}{|c|}{ Inicial } & \multicolumn{2}{|c|}{ Intermediário } & \multicolumn{2}{|c|}{ Final } \\
\hline Tentativa & $\begin{array}{c}\text { Carga } \\
(\mathrm{Kg})\end{array}$ & V/NV & Carga $(\mathrm{Kg})$ & V/NV & $\begin{array}{c}\text { Carga } \\
(\mathrm{Kg})\end{array}$ & V/NV \\
\hline 1 & & & & & & \\
\hline 2 & & & & & & \\
\hline 3 & & & & & & \\
\hline 4 & & & & & & \\
\hline 5 & & & & & & \\
\hline$\overline{1 R M}$ & & & & & & \\
\hline
\end{tabular}

V- Tentativa válida; NV - tentativa não válida.

\begin{tabular}{|c|c|c|c|c|c|c|}
\hline \multicolumn{6}{|c|}{ Teste de 1RM Cadeira Flexora } \\
\hline & \multicolumn{3}{|c|}{ Período do Treinamento } \\
\hline & \multicolumn{2}{|c|}{ Inicial } & \multicolumn{2}{c|}{ Intermediário } & \multicolumn{2}{c|}{ Final } \\
\hline Tentativa & $\begin{array}{c}\text { Carga } \\
(\text { Kg) }\end{array}$ & V/NV & Carga (Kg) & V/NV & $\begin{array}{c}\text { Carga } \\
(\text { Kg) }\end{array}$ & V/NV \\
& & & & & & \\
\hline 1 & & & & & & \\
\hline
\end{tabular}




\begin{tabular}{|c|l|l|l|l|l|l|}
\hline $\mathbf{2}$ & & & & & & \\
\hline 3 & & & & & & \\
\hline 4 & & & & & & \\
\hline $\mathbf{5}$ & & & & & & \\
\hline 1 RM & & & & & & \\
\hline
\end{tabular}

V- Tentativa válida; NV - tentativa não válida. 